\title{
Extracellular DNA traps released by acute promyelocytic leukemia cells through autophagy
}

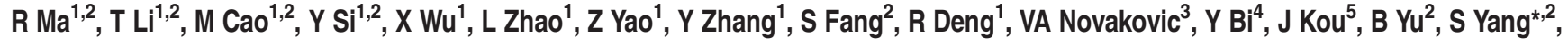 \\ $\mathrm{J} \mathrm{Wang}^{\star, 6}, \mathrm{~J}$ Zhou $^{*, 1}$ and J Shi ${ }^{*, 1,7}$
}

Acute promyelocytic leukemia (APL) cells exhibit disrupted regulation of cell death and differentiation, and therefore the fate of these leukemic cells is unclear. Here, we provide the first evidence that a small percentage of APL cells undergo a novel cell death pathway by releasing extracellular DNA traps (ETs) in untreated patients. Both APL and NB4 cells stimulated with APL serum had nuclear budding of vesicles filled with chromatin that leaked to the extracellular space when nuclear and cell membranes ruptured. Using immunofluorescence, we found that NB4 cells undergoing ETosis extruded lattice-like structures with a DNA-histone backbone. During all-trans retinoic acid (ATRA)-induced cell differentiation, a subset of NB4 cells underwent ETosis at days 1 and 3 of treatment. The levels of tumor necrosis factor- $\alpha$ (TNF- $\alpha$ ) and interleukin-6 (IL-6) were significantly elevated at 3 days, and combined treatment with TNF- $\alpha$ and IL- 6 stimulated NB4 cells to release ETs. Furthermore, inhibition of autophagy by pharmacological inhibitors or by small interfering RNA against Atg7 attenuated LC3 autophagy formation and significantly decreased ET generation. Our results identify a previously unrecognized mechanism for death in promyelocytes and suggest that ATRA may accelerate ET release through increased cytokines and autophagosome formation. Targeting this cellular death pathway in addition to conventional chemotherapy may provide new therapeutic modalities for APL.

Cell Death and Disease (2016) 7, e2283; doi:10.1038/cddis.2016.186; published online 30 June 2016

Acute promyelocytic leukemia (APL) is characterized by a chromosomal translocation $\mathrm{t}(15 ; 17)$, which interrupts the regulation of cell death, differentiation or division. ${ }^{1}$ Druginduced apoptosis and differentiation/apoptosis are regarded as the main mechanisms in anticancer therapy. ${ }^{2-4}$ However, a portion of patients undergo relapse partially due to the development of resistance to all-trans retinoic acid (ATRA) and arsenic trioxide (ATO) ${ }^{5-7}$ In addition, the fate of promyelocytes without chemotherapy is largely unknown. Thus, the mechanisms of cell death in APL need to be explored.

In 2004, Brinkmann et al. ${ }^{8}$ discovered a novel cell death program in neutrophils leading to the formation of extracellular traps (ETs) (NETs), termed NETosis, which differs both biochemically and morphologically from apoptosis. ${ }^{9-11}$ NET formation is involved in inflammatory responses, such as thrombosis and tissue injury. ${ }^{12-15}$ Although eosinophils, mast cells, monocyte and chronic myelocytic leukemia cell-derived neutrophils have been reported to release ETs, ${ }^{16-21}$ it remains unclear whether immature granulocytes like APL cells undergo ETosis. Recent reports showed that differentiation of $\mathrm{HL}-60$ cells, a human promyelocytic leukemia cell line, into mature neutrophils with calcium ionophore,
ATRA, or dimethyl sulfoxide or exposure to the glycosyltransferase inhibitor tunicamycin (TM) resulted in the formation of NET-like structures. $^{22-25}$ The nuclei of APL blasts lack lobules and the distribution of chromatin is loose, which are precursors to ET release. In this study, we hypothesized that APL cells are able to form extracellular DNA traps (ETs) and explored conditions under which APL cells are activated. Nuclear alterations occur when cells undergo differentiation; however, the effect of ATRA-induced APL cell differentiation on ET release is poorly understood. Autophagy has been shown to increase differentiation but impede apoptosis of APL cells. ${ }^{26-28}$ In this regard, autophagy plays an important part in cell regulation, and its role in APL cell ET formation needs to be elucidated. Taken together, the aim of our study was to clarify a novel cell death pathway of APL cells and provide new insights into the pathogenesis and evolution of APL.

\section{Results}

ET-forming death of APL cells is different from apoptosis. To know if immature granulocytes can undergo ETosis, cultured NB4 cells and APL cells isolated from patients were

\footnotetext{
${ }^{1}$ Department of Hematology of the First Hospital, Harbin Medical University, Harbin, China; ${ }^{2}$ The Key Laboratory of Myocardial Ischemia, Ministry of Education, Heilongjiang Province, Harbin, China; ${ }^{3}$ Department of Research, Brigham and Women's Hospital, VA Boston Healthcare System, and Harvard Medical School, Boston, MA, USA; ${ }^{4}$ Department of Cardiology of the First Hospital, Harbin Medical University, Harbin, China; ${ }^{5}$ Department of Cardiology of the Second Hospital, Harbin Medical University, Harbin, China; ${ }^{6}$ Department of Hematology of the Second Hospital, Harbin Medical University, Harbin, China and ${ }^{7}$ Department of Surgery, Brigham and Women's Hospital, VA Boston Healthcare System, and Harvard Medical School, Boston, MA, USA

*Corresponding author: J Shi or J Zhou, Department of Hematology, The First Hospital, Harbin Medical University, Harbin 150001, China. Tel: +1 8572035914 ; Fax: +1 857203 5592; E-mail: shi73661@gmail.com or jin_zhouxy@163.com

or J Wang or S Yang, Department of Medicine, The Second Hospital, Harbin Medical University, Harbin 150086, China. Tel: +86 45186605442 ;

E-mail: wang_jing_huaxy@163.com or shufen_yang@126.com

Abbreviations: APL, acute promyelocytic leukemia; ATO, arsenic trioxide; ATRA, all-trans retinoic acid; ETs, extracellular DNA traps; GAPDH, glyceraldehyde-3phosphate dehydrogenase; LC3, microtubule-associated protein 1 light chain 3; IL, interleukin; PI, propidium iodide; NE, neutrophil elastase; PMN, polymorphonuclear neutrophil; PS, phosphatidylserine; TEM, transmission electron microscopy; TM, tunicamycin; TNF, tumor necrosis factor

Received 04.1.16; revised 27.5.16; accepted 31.5.16
} 
a

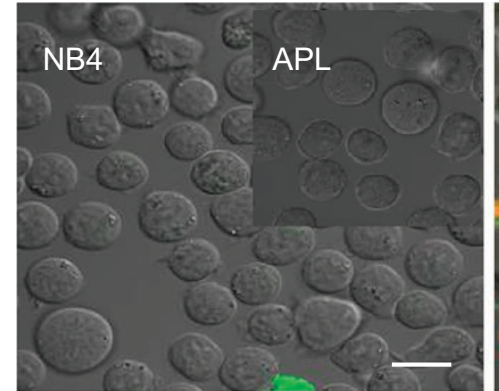

b
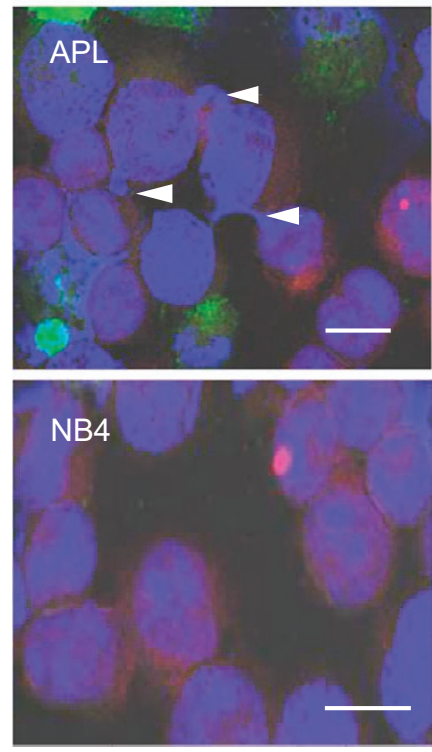

c
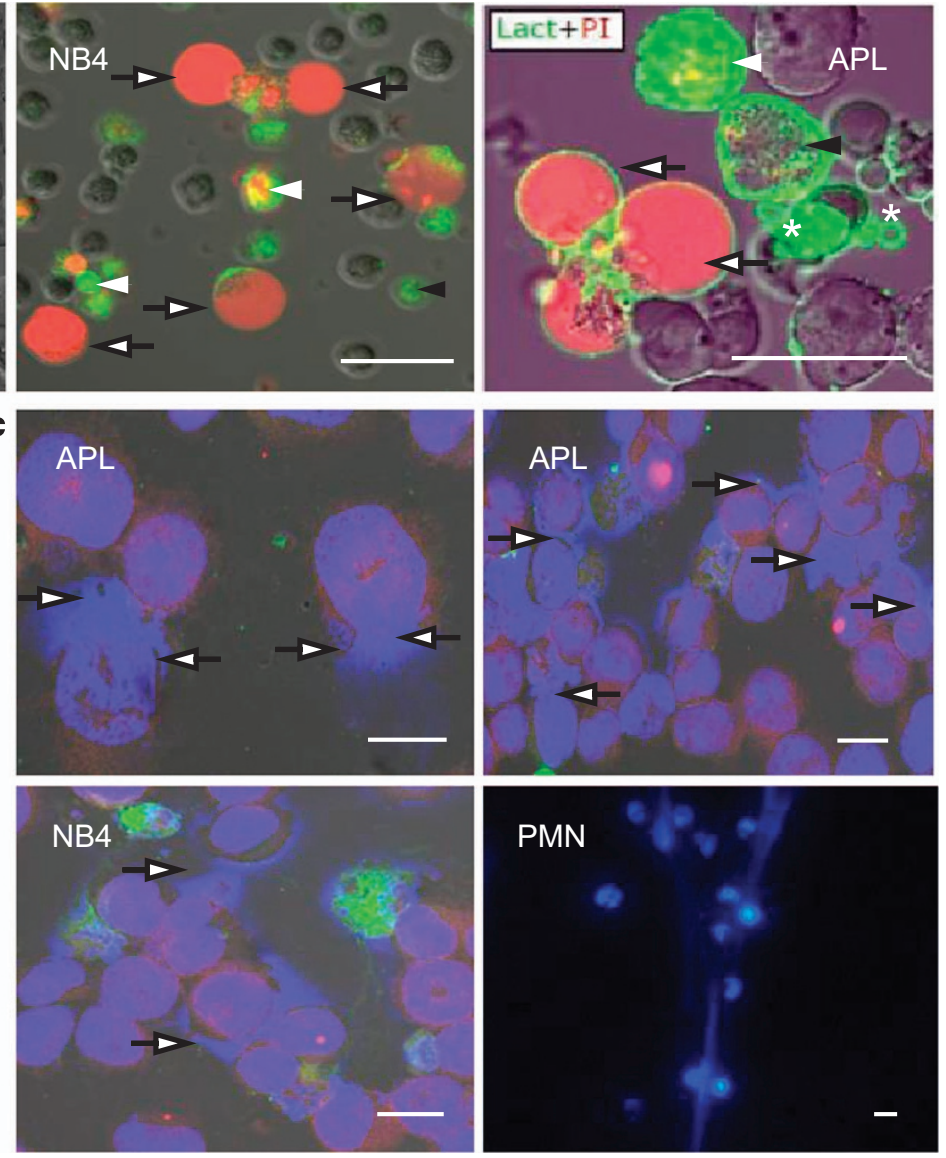
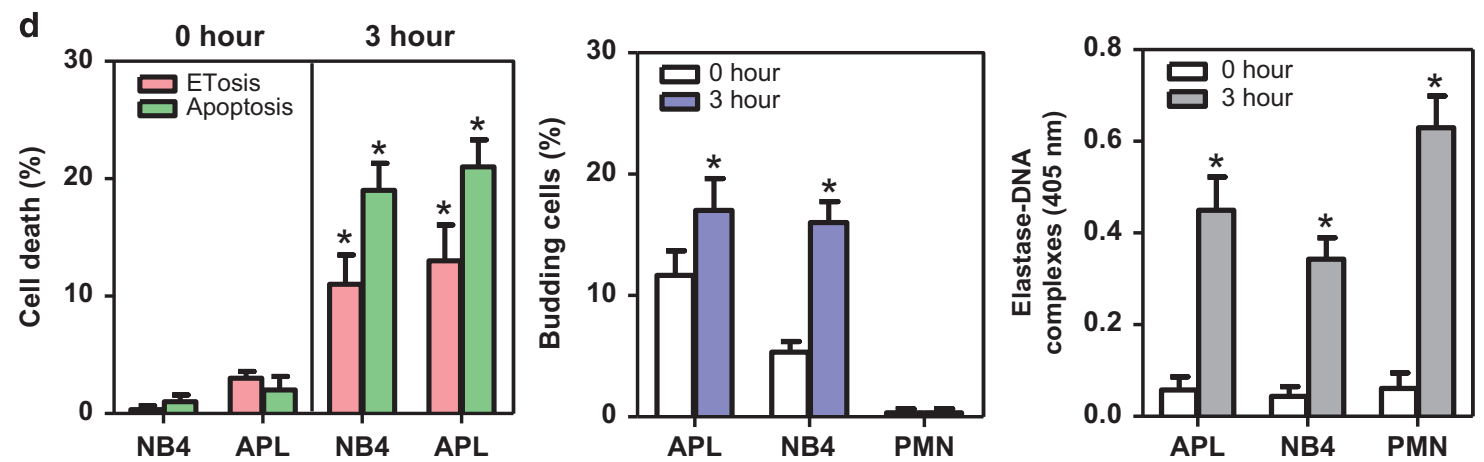

Figure 1 APL cells undergo novel death to form extracellular DNA traps. (a) NB4 and APL cells untreated or treated with APL serum for $3 \mathrm{~h}$ were stained with lactadherin (green) and PI (red). Confocal microscopy images showed that nuclei lost shape, expanded and filled most of the cytoplasm in treated NB4 cells (middle) and APL cells (right) (arrows). NB4 and APL cells undergoing early apoptosis showed diffuse rim staining by lactadherin but no PI staining (black arrowheads). Cells in late apoptosis had the nuclei that were condensed, fragmented (white arrowheads), and apoptotic bodies (*). Untreated NB4 and APL cells (left) showed little staining with either lactadherin or PI. Cells untreated (b) or treated with APL serum for $3 \mathrm{~h}$ (c) were stained with permeable DAPI (blue). Phosphatidylserine (green) and tissue factor (red) were also stained. Polymorphonuclear leukocytes (PMN) treated with APL serum for $3 \mathrm{~h}$ were used as a control. Budding cells (white arrowheads), extracellular DNA traps (arrows). (d) Cells undergoing ETosis or apoptosis were counted and analyzed as described in Materials and Methods $(n=5)$. Concentration of Elastase-DNA complexes was also measured $(n=5)$. All values are means \pm S.D. ${ }^{*} P<0.05$ versus $0 \mathrm{~h}$. Bars represent $20 \mu \mathrm{m}(\mathbf{a})$ and $15 \mu \mathrm{m}(\mathbf{b}$ and $\mathbf{c})$

incubated with serum from APL patients for $3 \mathrm{~h}$. The phosphatidylserine (PS) probe lactadherin and propidium iodide $(\mathrm{PI})$ were added to distinguish ETosis from apoptosis (Figure 1a). Little fluorescent staining or morphologic alterations were observed in untreated NB4 and APL cells (Figure 1a, left). Some serum-treated NB4 and APL cells were observed undergoing both ETosis and apoptosis
(Figure 1a, middle and right). Apoptosis was defined as the presence of membrane blebbing and nuclei fragmentation. The cell membranes of apoptotic cells also stained strongly with lactadherin (green) as a result of the PS expression on the outside of the cell membrane. Cells at later stages of apoptosis after their cell membrane integrity was disrupted stained with PI (red). In contrast, a small subset of NB4 or 
APL cells underwent a different type of cell death (Figure 1a, middle and right). In these cells, nuclei stained with $\mathrm{PI}$ became rounded and nuclear contents rapidly diffused throughout the cell rather than degrading. The PI staining was in the absence of lactadherin membrane staining (green) or visible membrane blebbing. However, due to disruption of the cell membrane, lactadherin did leak into the cell leading to some weak staining (Figure 1a). Permeable 4',6-diamidino-2phenylindole (DAPI) staining was used to further observe the nuclear changes. We found that fresh APL cells showed a tendency towards deformed nuclei with blebbings (Figure 1b). After treatment with patient serum, some APL and NB4 cells showed disintegrated plasma membranes with their cellular components beginning to leak into the extracellular environment (Figure 1c). In contrast, polymorphonuclear leukocytes (PMN) spat out nuclear structures after treatment with APL serum. About $13 \%$ APL cells and $10 \%$ NB4 cells underwent ETosis when incubated with APL serum for $3 \mathrm{~h}$, and $21 \%$ APL cells and $17 \%$ NB4 cells were apoptotic (Figure 1d).

Nuclear vesicles and breakdown allow the formation of ETs. We used transmission electron microscopy (TEM) to investigate the morphological changes leading to ETosis, and distinguish it from apoptosis and necrosis. Untreated APL cells had non-segmented nuclei with intact nuclear membranes (Figure 2a). Apoptosis was induced by incubating APL cells with daunorubicin (DNR) for $24 \mathrm{~h} .{ }^{29}$ Apoptotic APL cells showed the classical morphology, including condensation of chromatin and fragmentation of nuclei without rupture of the nuclear envelope, as well as apoptotic body formation (Figure 2b). Necrosis was triggered by subjecting cells to four freeze/thaw cycles. ${ }^{30}$ Necrotic cells were characterized by the loss of nuclei structure and fusion of lobules into a homogeneous mass without segregation into euchromatin and heterochromatin (Figure 2c). APL cells were treated with patients' serum for different time points. When cultured for $1 \mathrm{~h}$, a small percentage of APL cells showed a massive dilation between the inner and outer nuclear membranes referred to as blebbing (Figures $2 d$ and e). The inner membrane was ruptured to release decondensed DNA into this separation (Figure 2e). After $2 \mathrm{~h}$ incubation, DNA strands were visible inside vesicles in the cytoplasm. It is worth noting that in the early stages of vesicle formation, the nuclei maintained intact nuclear pore complexes, and breakdown of the nuclear membrane was not evident. The DNA-containing vesicles then merged with granules (Figure 2f) and fused with the plasma membrane to empty their contents and form ETs (Figure 2g). APL cells eventually underwent complete nuclear envelope breakdown, releasing DNA material into the cytoplasm at $3 \mathrm{~h}$ incubation (Figure $2 \mathrm{~h}$ ) and then into the extracellular space when the plasma membrane was disrupted (Figure 2i). Thus, cells forming ETs can be distinguished from necrotic cells in that the nuclear membranes remained intact until the latest stage of cell death.

APL cells release elastase-DNA complexes. Using immunofluorescence, we were able to identify the components of ETs that were released by APL cells. We found that the granule-marker elastase co-localized with the DNA-histone backbone (Figure 3a). Untreated APL cells from patients released ETs to a lesser extent compared with those treated with APL serum. Based on the recently proposed correlation between circulating nucleosomes, granulocyte activation and ETosis, MPO-DNA or elastase-DNA complexes content in serum was measured as an indirect marker of in vivo ET formation. $^{31,32}$ We found that the elevated ET release in treated APL cells was paralleled by an increased abundance of plasma elastase-DNA complexes (Figure $3 \mathrm{~b}$ ), which was also seen in APL patients in comparison with healthy controls (data not shown). Immunofluorescence and western blot were utilized to measure the apoptosis marker caspase-3 (Figures $3 c$ and d). We found that caspase-3 expression increased in serum-treated APL cells compared with untreated ones, consistent with the finding that more APL cells underwent apoptosis after $3 \mathrm{~h}$ of serum treatment (Figure 1d). However, little staining of caspase-3 was seen in ET-releasing APL cells (Figure 3d), providing evidence that ETosis is distinct from apoptosis.

ATRA induces APL cell differentiation potentiating ET formation. NB4 cells showed apparent morphology changes after 1 day of ATRA treatment (Figure 4a). A marked decrease in the nuclear-cytoplasmic ratio was observed after 3 days, and about $12 \%$ of NB4 cells had deformed nuclei with the chromatin permeating through the cytoplasm or released from the cells. Apoptotic cells exhibited nucleus concentration and cell shrinkage, which differentiated them from cells undergoing ETosis (Figure 4b). After 5 days, NB4 cells showed cell collapse, indicating late apoptosis. The percentage of cells observed undergoing ETosis peaked at $15 \%$ on day 3 (Figure $4 \mathrm{c}$ ). Because ATRA syndrome is characterized by excessive cytokine release, ${ }^{33}$ we measured tumor necrosis factor- $a$ (TNF- $a$ ) and IL-6 generation in supernatants. Both TNF- $a$ and IL-6 were significantly higher in ATRA-treated cells on day 3 (Figure $4 d$ ). Furthermore, the levels of TNF- $a$ and IL- 6 were higher in APL patients compared with healthy subjects (data not shown).

Autophagy is involved in ET formation. The previously described implication of autophagy in ET release prompted us to investigate whether autophagy contributes to ET formation in APL. ${ }^{34}$ NB4 cells were treated with patients' serum for different time points (Figure 5a) and we found an increase in LC3-positive structures (autophagosomes) and ET formation in a time-dependent fashion. Minimal LC3 aggregation was observed after 30 minutes ( $\mathrm{min}$ ) of stimulation, which was upregulated at $60 \mathrm{~min}$. Of interest, histone colocalization with LC3 was observed in the cytoplasm, indicating that autophagosomes wrapped nucleosomes. LC3 expression (measured by immunofluorescence and western blot) increased in a time-dependent manner. However, LC3 aggregated at the $3 \mathrm{~h}$ time point when ET were released making quantitation by immunofluorescence difficult (Figure 5a). ET release was observed at $3 \mathrm{~h}$ of stimulation with $13 \%$ of NB4 cells releasing DNA threads (Figure $6 \mathrm{c}$ ). Recent studies suggest that ATRA is closely associated with autophagy in cell differentiation, motivating us to explore whether autophagy contributes to ET formation in 

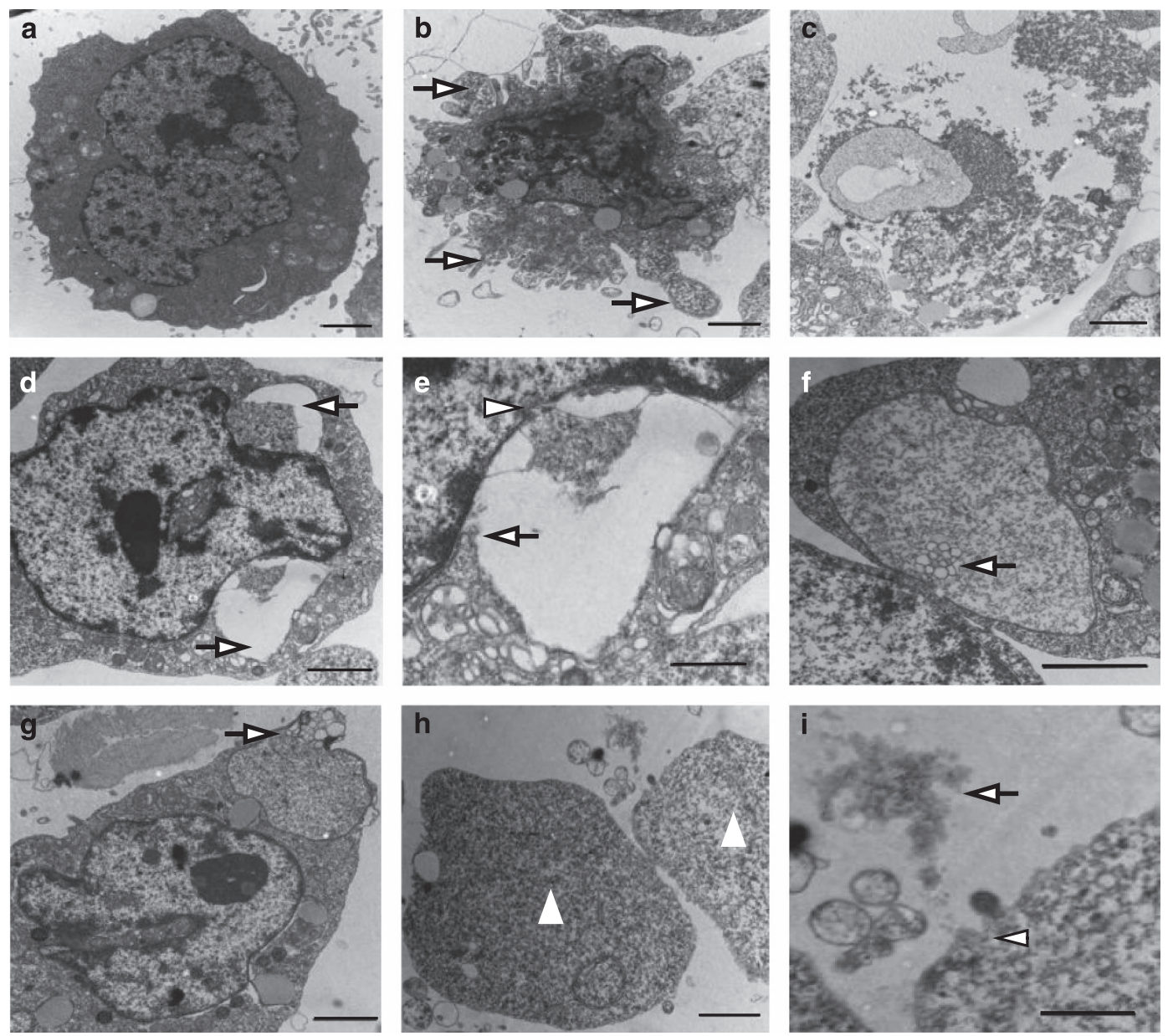

Figure 2 ET-forming death can be distinguished from apoptosis using transmission electron microscopy. (a) Normal APL blasts had non-segmented nucleus with intact nuclear membranes. (b) APL cells treated with DNR showed characteristic apoptotic morphology, including apoptotic body formation with nuclear condensation and fragmentation (arrows). (c) Necrosis in APL cells was characterized by the loss of segregation into euchromatin and heterochromatin while the nuclear envelope remained intact. (d-i) APL cells were cultured in APL serum for different time points. (d and e) After $1 \mathrm{~h}$ incubation, inner and outer nuclear membranes separated forming a dilation (arrows) and local magnification showed inner membrane fractured to release nuclear contents into the dilation (arrowhead) while the outer membrane remained intact (arrow). ( $\mathrm{f}$ and $\mathbf{g}$ ) Later (at $2 \mathrm{~h}$ incubation), nuclear vesicles merged with granules (arrow) and fused with the plasma membrane to extrude DNA material into extracellular space. (h) In end stage (at $3 \mathrm{~h}$ incubation), the nuclear envelope ruptured, and DNA filled the cytoplasm leading to cell lysis (triangles). (i) Ultimately, the plasma membrane broke (arrowhead) and DNA lattice was released (arrow). Bars represent $2 \mu \mathrm{m}(\mathbf{a}-\mathbf{d}, \mathbf{f}-\mathbf{h})$ and $1 \mu \mathrm{m}$ (e and i)

ATRA-treated APL cells. NB4 cells were treated with ATRA for 3 days or stimulated with TNF- $a$ and IL- 6 for $1 \mathrm{~h}$. ET release was significantly increased in ATRA or cytokinetreated NB4 cells in comparison with untreated NB4 cells (Figure 5b). TEM further confirmed that NB4 cells underwent autophagy when stimulated by APL serum or ATRA or cytokines, as indicated by the extensive vacuolization and the formation of typical autophagosomes, defined at the ultrastructural levels by a double membrane (Figures $5 a$ and $b$ ). The increased numbers of autophagosomes observed by TEM in APL serum or ATRA or cytokine-treated NB4 cells were consistent with enhanced LC3 staining (Figure 5d). These results indicate that autophagy does occur when APL cells undergoing ETosis.

Blocking autophagy attenuates ET release by NB4 cells. NB4 cells were cultured with APL serum for $3 \mathrm{~h}$ in the presence of various autophagy inhibitors (5'-(4-fluorosulfonylbenzoyl) adenosine hydrochloride (wortmannin), 3-methyladenine (3-MA) or bafilomycin) resulting in significantly decreased ET release (Figure 6a). For further experiments, NB4 cells were treated with APL serum ( $3 \mathrm{~h}$ ) or ATRA (3 days) or TNF- $a$ and IL-6 $(1 \mathrm{~h})$ with or without wortmannin, which blocks autophagic flux. In all three groups, wortmannin inhibited both LC3 aggregation and the ET release (Figure 6b). Elastase-DNA complexes in supernatants also decreased with wortmannin treatment (Figure 6c). Furthermore, we knocked down autophagy-related gene Atg7 using small interfering RNA (siRNA) to confirm the role of autophagy in ETosis in APL. ${ }^{35}$ As shown in Figure $7 \mathrm{a}$, inhibition of autophagy nearly abolished APL serum-induced autophagy as the markedly decreased conversion of LC3B-I to LC3B-II. Knocking down of Atg7 (supplementary figure) resulted in significantly reduced ET release and LC3 expression by immunofluorescence (Figure 7c) and elastase-DNA complexes generation (Figure $7 \mathrm{~b}$ ). Combined with results in Figure 5, we suggest 
a
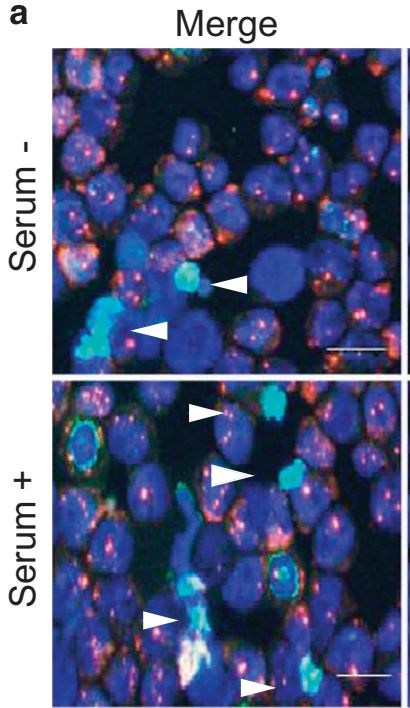

b

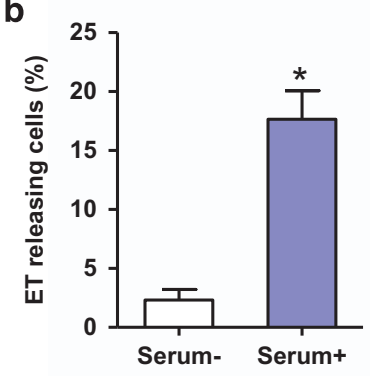

d

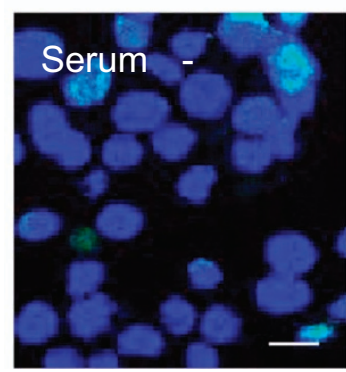

DNA
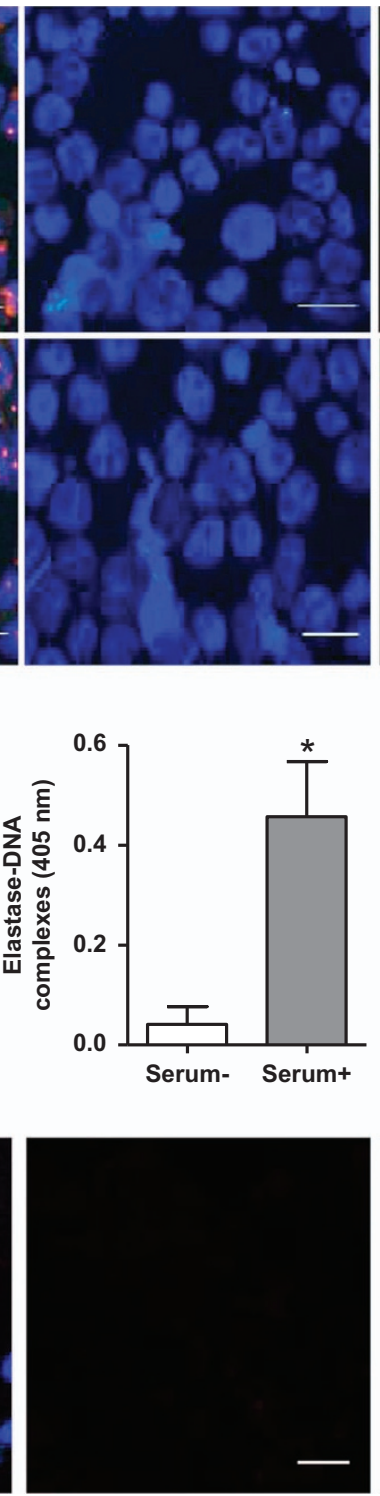

Histone
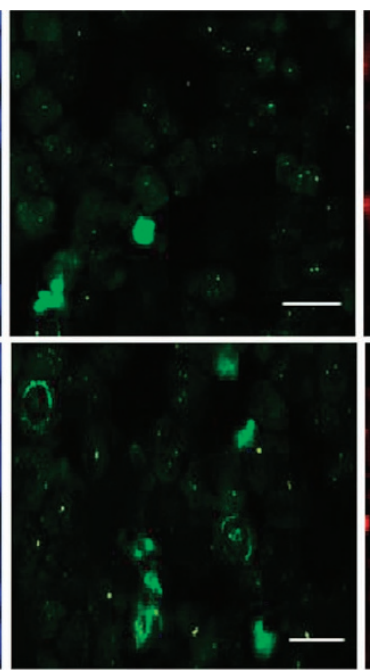

C

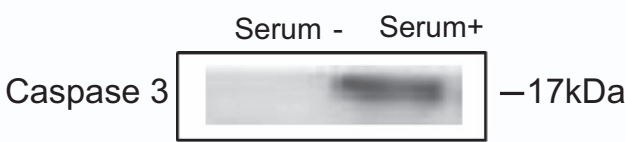

Actin
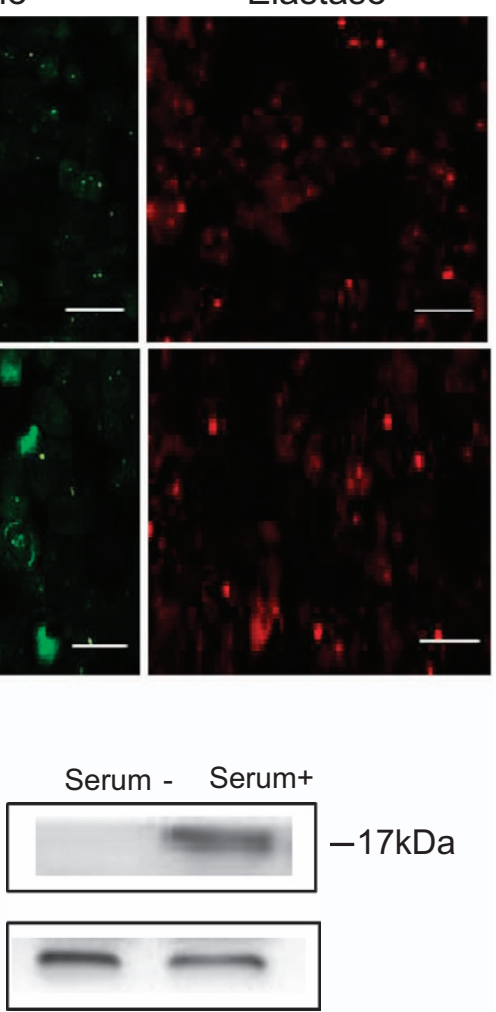

Figure 3 Promyelocytes release elastase-DNA complexes. (a) Immunostaining of extracellular DNA traps released by untreated APL cells (upper) or after treatment with APL serum for $3 \mathrm{~h}$ (low). Extracellular traps (arrowheads) were characterized by DNA (blue), histone H3 (green) and granule-marker elastase (red). (b) Quantification of ETs showed a significant increase in treated APL cells compared with those untreated, consistent with the concentration of elastase-DNA complexes $(n=3)$. All values are means \pm S.D. ${ }^{*} P<0.05$ versus serum - . (c) Caspase-3 expression was measured by western blot in APL cells that were untreated or treated with APL serum for $3 \mathrm{~h}$. (d) APL cells untreated or treated with APL serum for $3 \mathrm{~h}$ were co-stained with DAPI (blue), anti-histone H3 (green) and anti-caspase-3 (red). Immunostaining images of DAPI/Histone/ caspase-3 merged (left) or caspase-3 alone (right). APL cells underwent ETosis (arrowhead) with little caspase-3 stain. Bars represent $15 \mu \mathrm{m}$ (a and $\mathbf{d}$ )

that APL serum/ATRA/cytokine-induced ET release by NB4 cells may proceed in an autophagy-dependent manner.

\section{Discussion}

In this study, we have shown for the first time that APL blasts release intact chromatin into the extracellular space leading to ET formation. The changes follow a particular pattern that is initiated by the dilation of the inner and outer nuclear membranes. After that, ETosis is characterized by nuclear vesicle formation and exocytosis to extrude DNA strands. Later, APL cells undergo nuclear envelope and cell membrane breakdown, allowing the DNA traps to leak out. It is worth noting that ET-forming death is distinct from apoptosis and necrosis in morphology, suggesting a novel cell death pathway. More importantly, the vesicles used by APL cells to deliver DNA traps are distinct from those used by PMNs when spitting out DNA strands, and the dynamics of these mechanisms need to be further studied. The main components of ETs are DNA and histone which are procoagulant substances. $^{36,37}$ Recent studies have implicated ETs in thrombotic events in acute myocardial infarction, venous thromboembolism, tumor, etc. ${ }^{38-41}$ The role of ETs in the pathogenesis and coagulopathy of APL needs further study. 
a

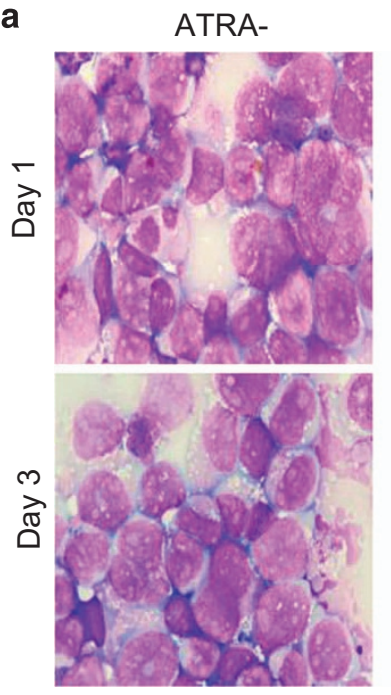

ATRA+
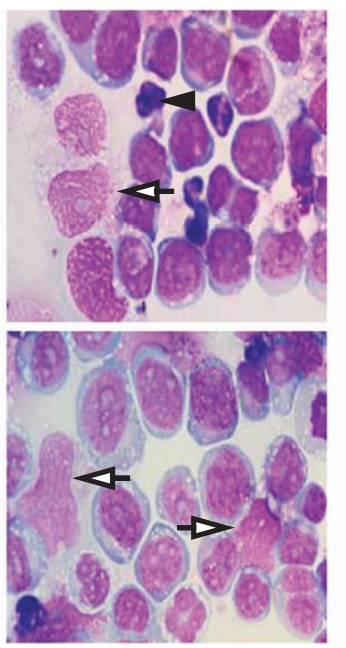

b
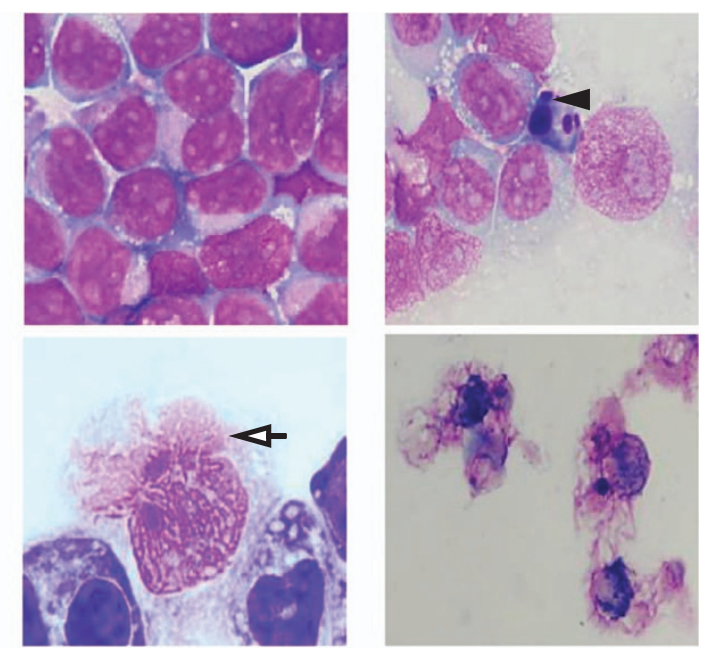
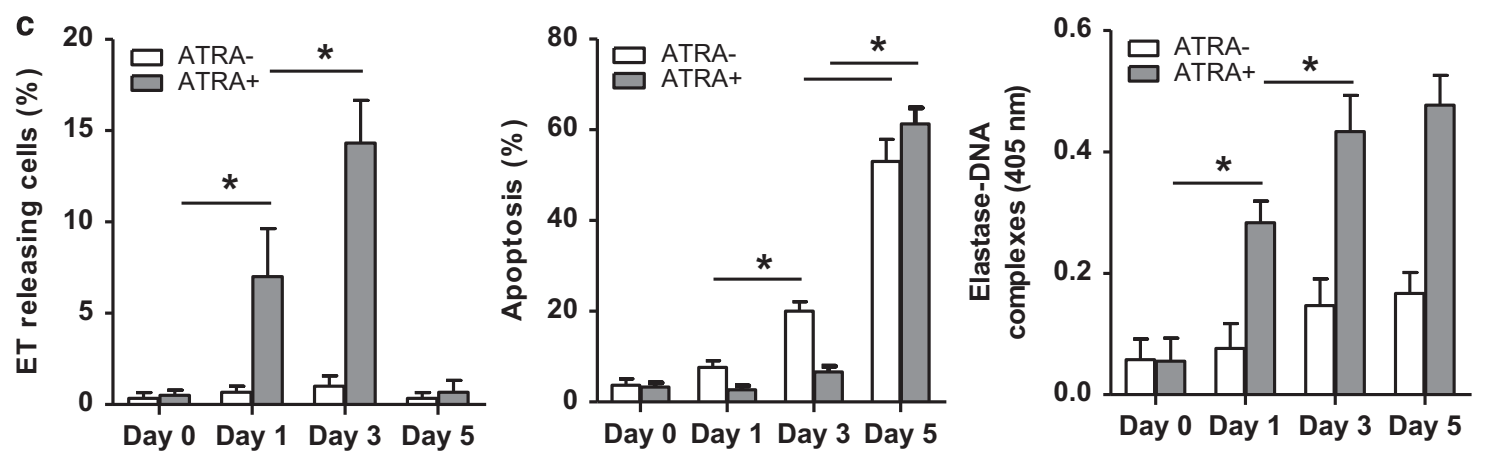

d

TNF- $\alpha$
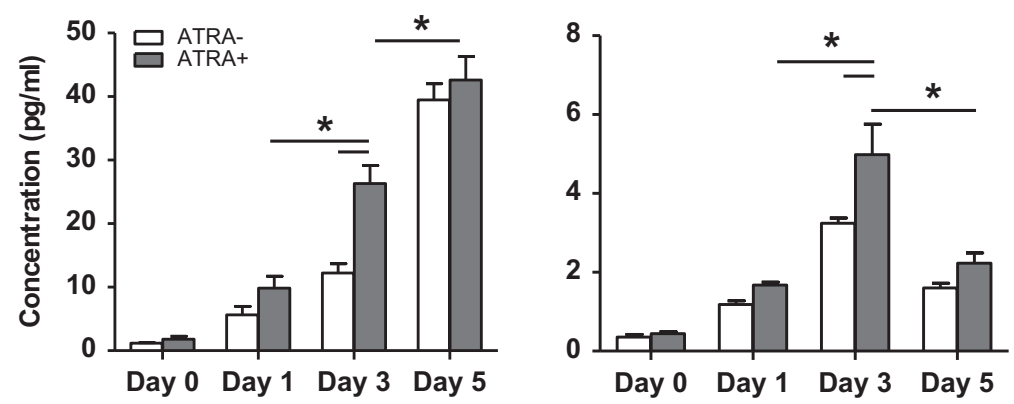

Figure 4 ATRA triggers ET release by NB4 cells during differentiation. NB4 cells were cultured with ATRA $(1 \mu \mathrm{M})$ for different time points and observed on a light microscope. (a) NB4 cells treated for 1 day (upper) and 3 days (lower) were stained with Wright-Giemsa staining, and cell differentiation and nuclear-cytoplasmic ratios were observed. Some NB4 cells died by ETosis (arrows) and apoptosis (arrowhead) during ATRA treatment. Magnification $\times 100$. (b) Representative images of cells undergoing apoptosis (upper right, arrowhead) and ETosis (lower left, arrow). After 5 days of treatment, a majority of NB4 cells were undergoing late apoptosis (lower right). Untreated NB4 cells served as a control (upper left). Magnification $\times 100$. (c) ATRA-treated NB4 cells were characterized by morphology, and the percentage of ET-releasing cells and apoptotic cells were determined $(n=5)$. Concentration of elastase-DNA complexes was also measured $(n=5)$. All values are means \pm S.D. ${ }^{*} P<0.05$. (d) The concentration of TNF- $\alpha$ and IL-6 in supernatants was detected with sandwich ELISA using a microplate reader $(n=5)$. All values are means \pm S.D. ${ }^{*} P<0.05$

ATRA is acknowledged to induce cell differentiation and is widely used in APL patients. However, we report for the first time that about $10 \%$ of cells undergo ETosis instead of differentiation during ATRA treatment. In a time-dependent manner, TNF- $a$ and IL- 6 concentrations are increased in ATRA-treated APL cells. Additionally, combined treatment with
TNF- $a$ and IL- 6 is capable of stimulating APL cells to release ETs. Given these results, we speculate that ATRA both accelerates cell differentiation and induces cells to release more cytokines, such as TNF- $a$ and IL-6. TNF- $a$ and IL- 6 are potent stimuli of granulocytes. ${ }^{42,43}$ Thus ATRA may promote APL cells to generate ETs through TNF- $a$ and IL- 6 activating 
pathways. Furthermore, recent studies have suggested that ATRA promotes differentiation of APL cells by inducing degradation of the PML-RARa oncoprotein. Whether the incomplete degradation of PML-RARa oncoprotein or another ATRA-induced signal pathway contributes to ETosis is largely unknown and urgently needs studying. This could provide important clues for ATRA-associated drug resistance and new therapeutic targets.

Autophagy is a well-conserved, essential, intracellular degradation process and occurs when cells respond to stress or undergo death. ${ }^{4-46}$ Recent studies demonstrate that parts of the nucleus can be specifically degraded by an autophagic process termed nucleophagy. ${ }^{47}$ In this study, we find that in the early stage of ETosis, nuclear material are sequestered and packed in vesicles. Colocalization of DNA-histone and LC3 is also seen, suggesting that nucleophagy may be the cause of the nuclear vacuolization that initiates ETosis. However, the nuclear vesicles mix with granules and are released to the extracellular space, and ultimately the autophagosomes merge when ET form. This is consistent with the morphology of cell lysis in the end stage of ET release and different from nucleophagy. Further, inhibiting autophagy attenuates ET formation in APL serum, ATRA or cytokine-treated APL cells. These results indicate that autophagic sequestration of part of a
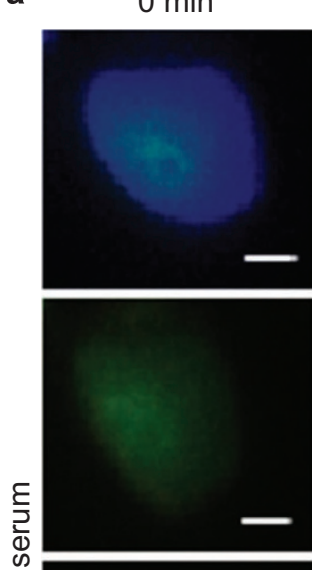

¿
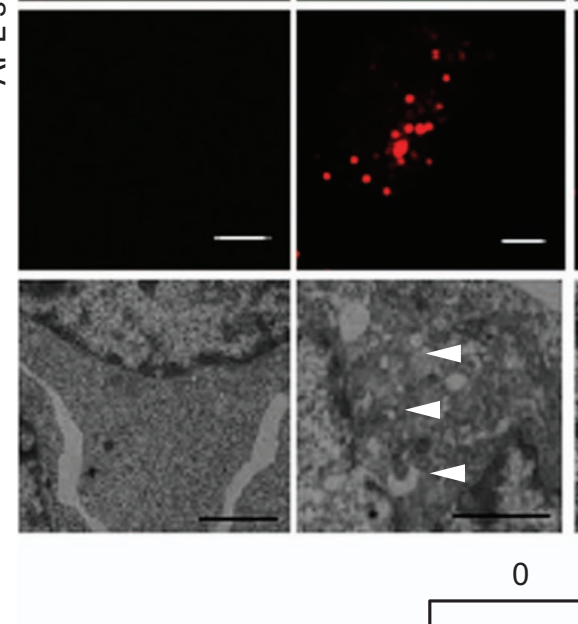

$30 \mathrm{~min}$
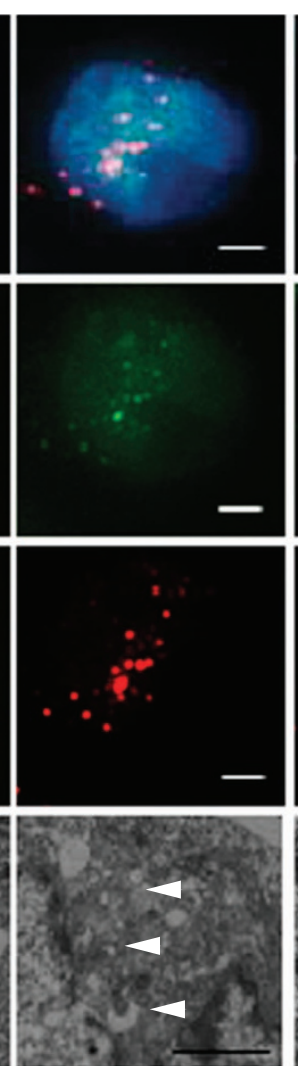

$60 \min$
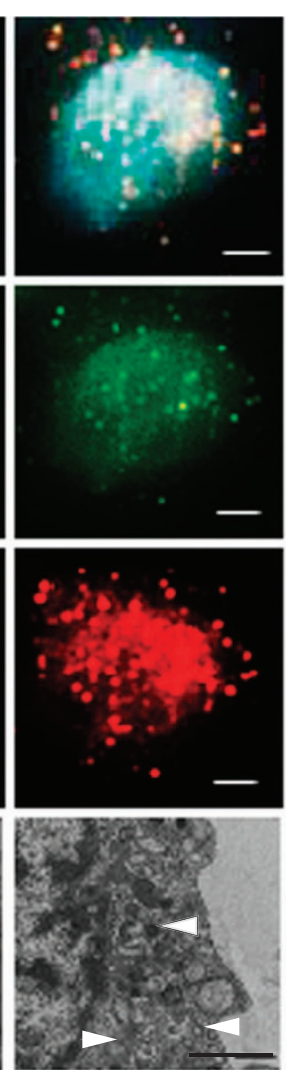

$60-120$
$180 \min$
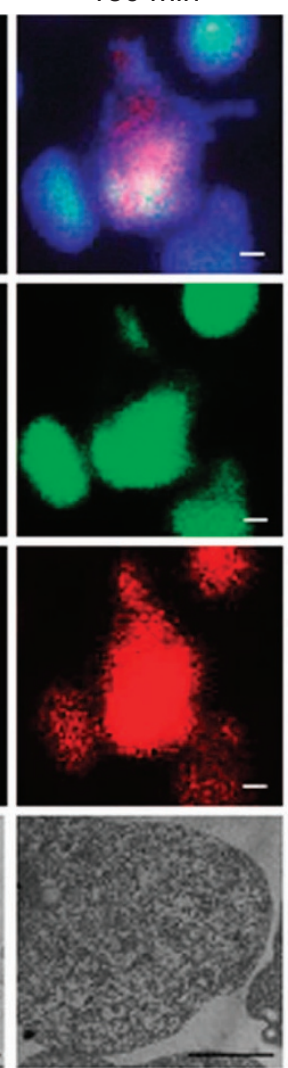

$180 \quad 180 / \mathrm{Ctrl}$
$180 \mathrm{~min} / \mathrm{Ctr}$
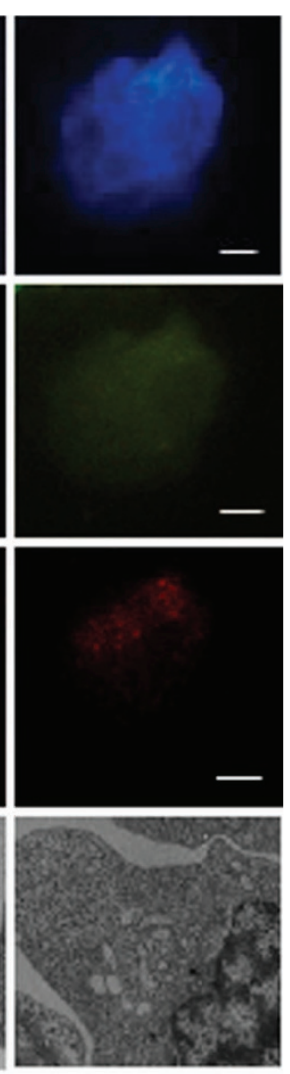

$(\min )$

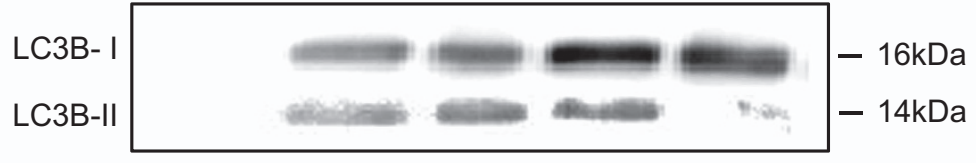

Actin

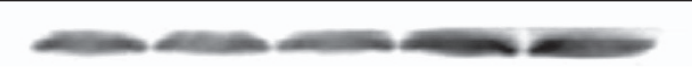

Figure 5 Autophagy is involved in ET formation. (a) NB4 cells were incubated with serum from APL patients for different time points and measured by immunofluorescence assays (IF). ET and autophagosome formation were detected by DNA-histone and LC3 positivity, respectively. LC3-coated structures (red) and histones (green) co-localized (yellow) as seen in the merged images. LC3 aggregation accompanied ET release at $3 \mathrm{~h}$. NB4 cells treated with serum from healthy subjects served as controls. LC3I and LC3II expression were measured by western blot. (b) NB4 cells were incubated with ATRA for 3 days or stimulated with TNF- $\alpha$ and IL- 6 for $1 \mathrm{~h}$. Cells were stained with DAPI (blue), antihistone (green) and anti-LC3 (red). Untreated NB4 cells were used as a control. Transmission electron microscopy (TEM) images further confirmed the presence of doublemembrane autophagosomes (arrowheads) during the process of ETosis (a and $\mathbf{b})$. (c) The LC3 puncta per cell in APL serum-treated NB4 cells measured by IF ( $n=3)$. (d) The number of autophagosomes observed by TEM was calculated in APL serum (left panel) and ATRA or cytokine (right panel) treated NB4 cells $(n=3)$. All values are means \pm S.D. ${ }^{*} \mathrm{P}<0.05$. Bars represent $2(\mathbf{a}), 15(\mathbf{b}, \mathrm{IF})$ and $1 \mu \mathrm{m}(\mathbf{b}, \mathrm{TEM})$ 
b
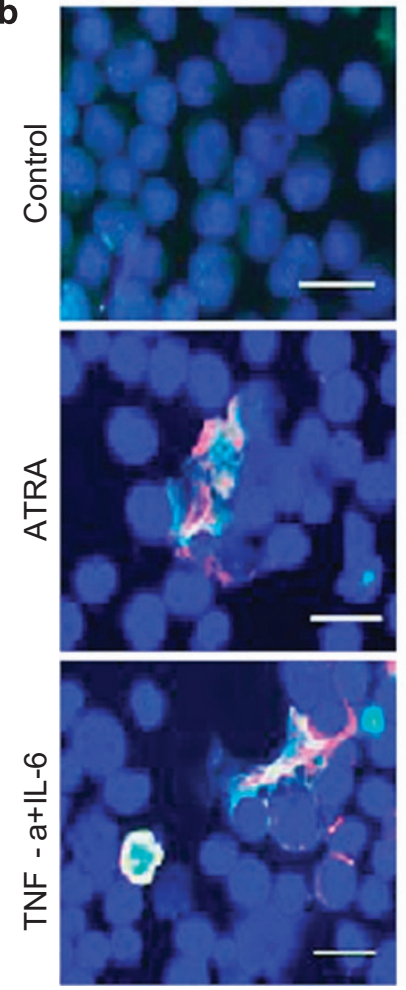

C

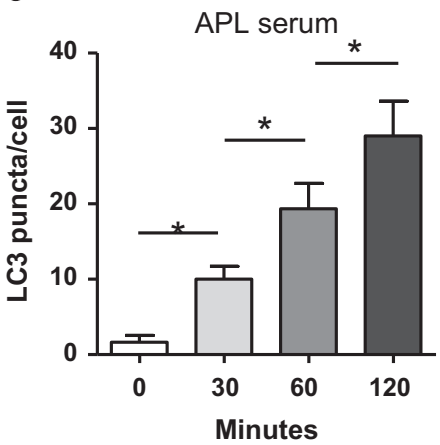

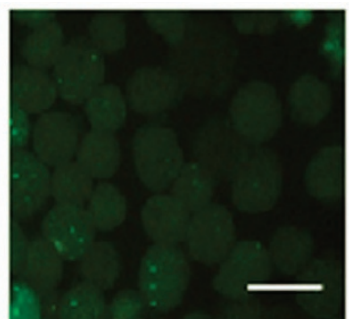
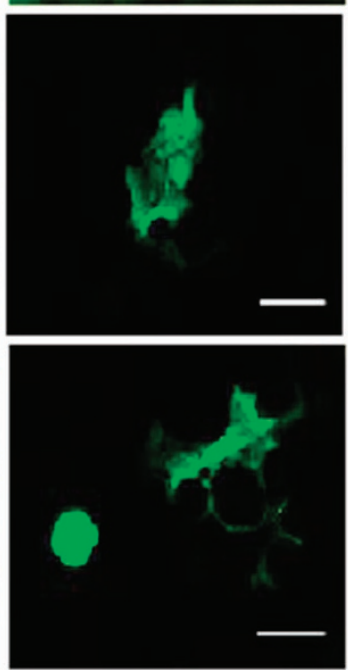
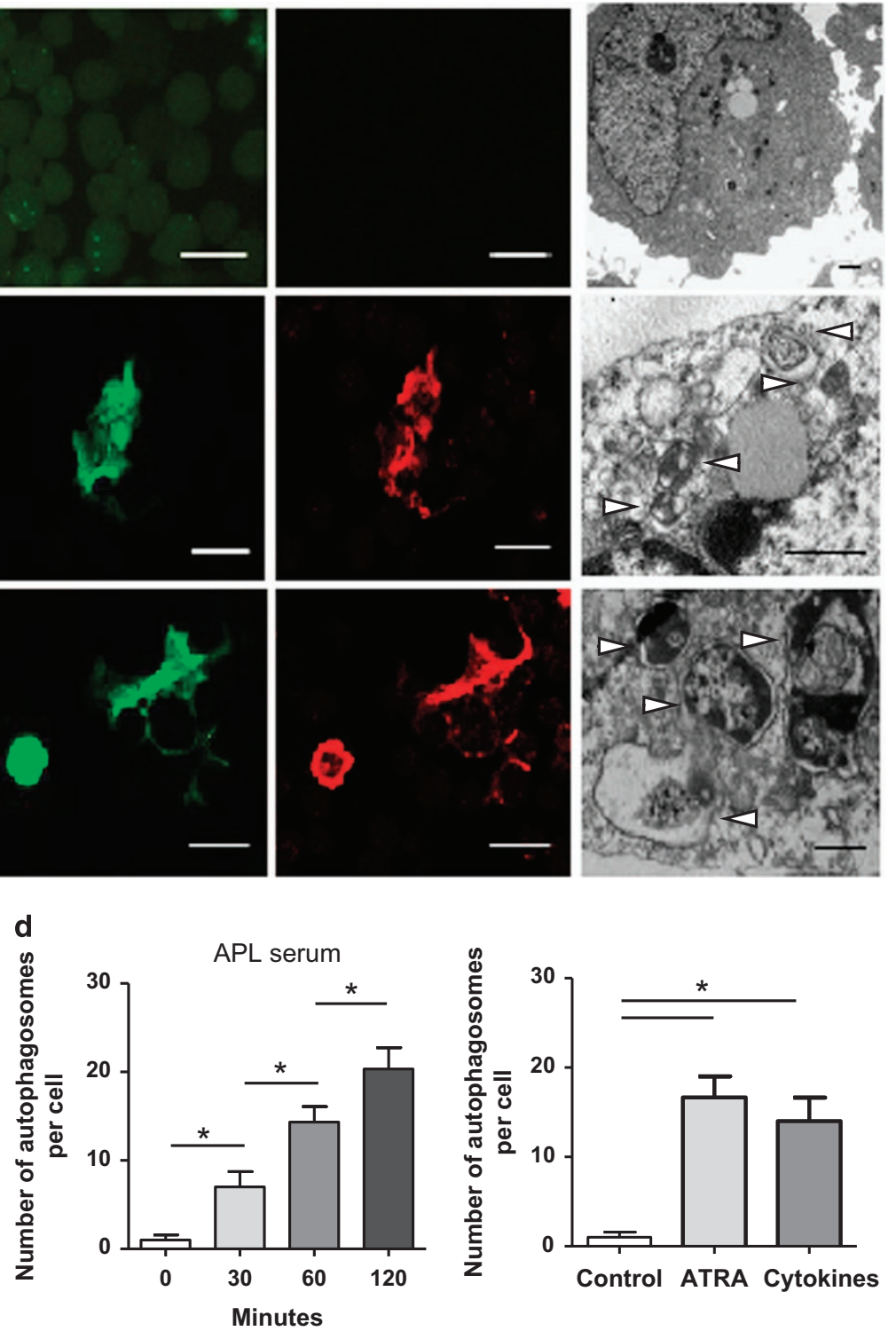

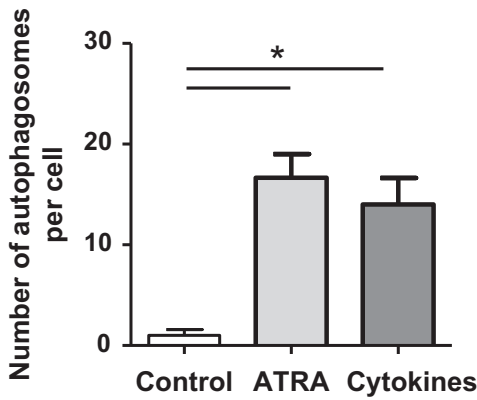

Figure 5 Continued

the nucleus may be the initiation of ETosis and nuclear degradation by autophagy may contribute to the elimination of abnormal oncogenes. ${ }^{48,49}$ Furthermore, the molecular mechanisms involved in nuclear autophagy in APL cells need to be further studied.

APL has evolved from being a deadly to a highly curable disease, due to combined treatments of ATRA with ATO or chemotherapy. However, drug resistance and recurrent disease are still critical problems in APL. As a different cell death pathway, ETosis is considered as important as apoptosis for its widespread existence in various physiologic and pathologic conditions. In this regard, ETosis as well as apoptosis are inherent self-regulation pathways in APL. If applied in clinical treatment, induction of APL cell ETosis could be an alternative to killing tumor cells. Our study provides new insights into the regulatory mechanism of cell death, further insights into the evolution of promyelocytes and pathogenesis, and potential points of molecular intervention strategies in APL patients. Our results, showing the release of intact chromatin decorated with cytoplasmic proteins into the extracellular space by APL cells, are unprecedented and demonstrate a novel cell death pathway that warrants further investigation.

\section{Materials and Methods}

Patients. Venous peripheral blood and bone marrow were obtained from 16 newly diagnosed APL patients admitted to the First and Second Affiliated Hospital of Harbin Medical University between May 2014 and February 2015. Informed written consent was obtained from every patient or their relatives. The diagnosis was based on clinical data, morphology, cytochemistry, immunology, cytogenetics and molecular biology. ${ }^{29}$ Cytogenetic analysis indicated the presence of $t(15 ; 17)$ translocation and PML/RAR $\alpha$ fusion gene in all cases. The main characteristics of the patients are reported in Table 1. This study was approved by Ethics Committee of Harbin Medical University and conducted in accordance with the Declaration of Helsinki. 
a

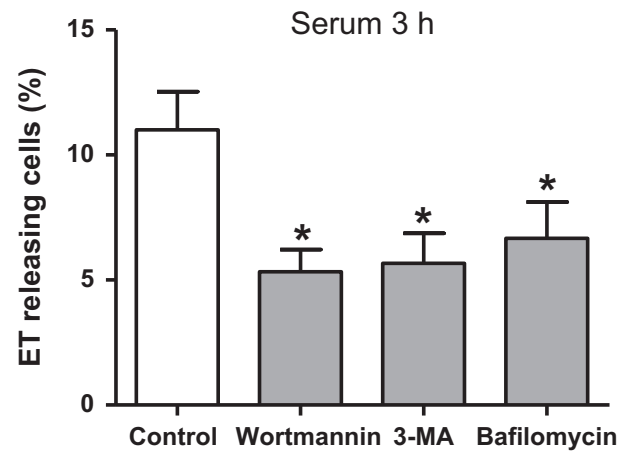

b
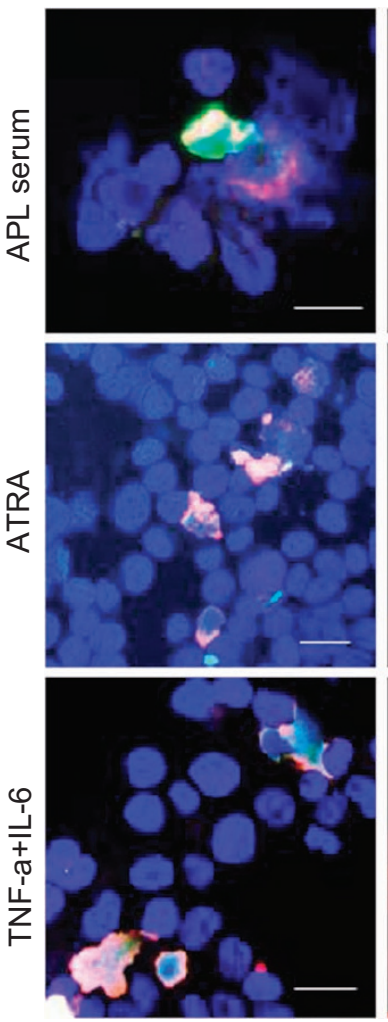

C
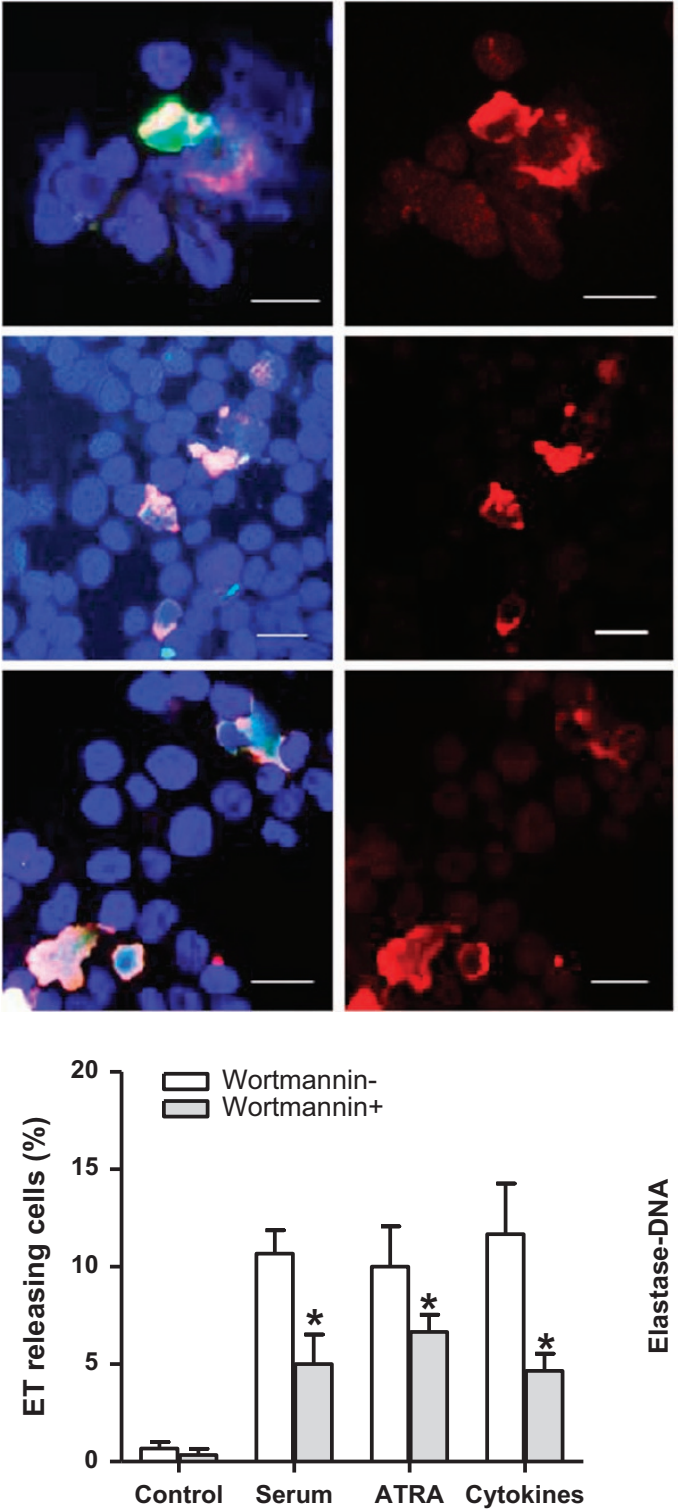

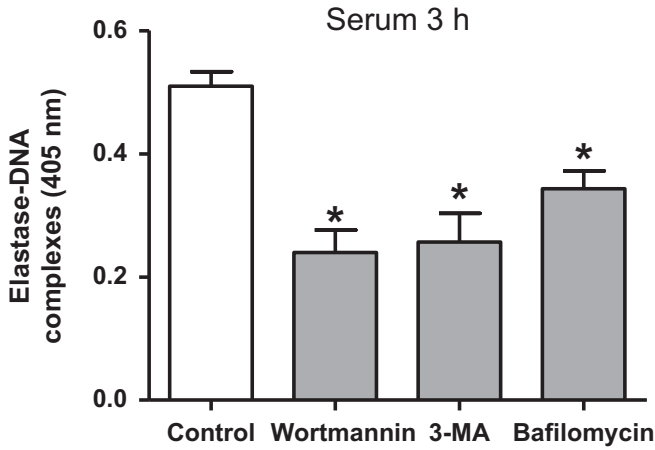

Wortmannin+
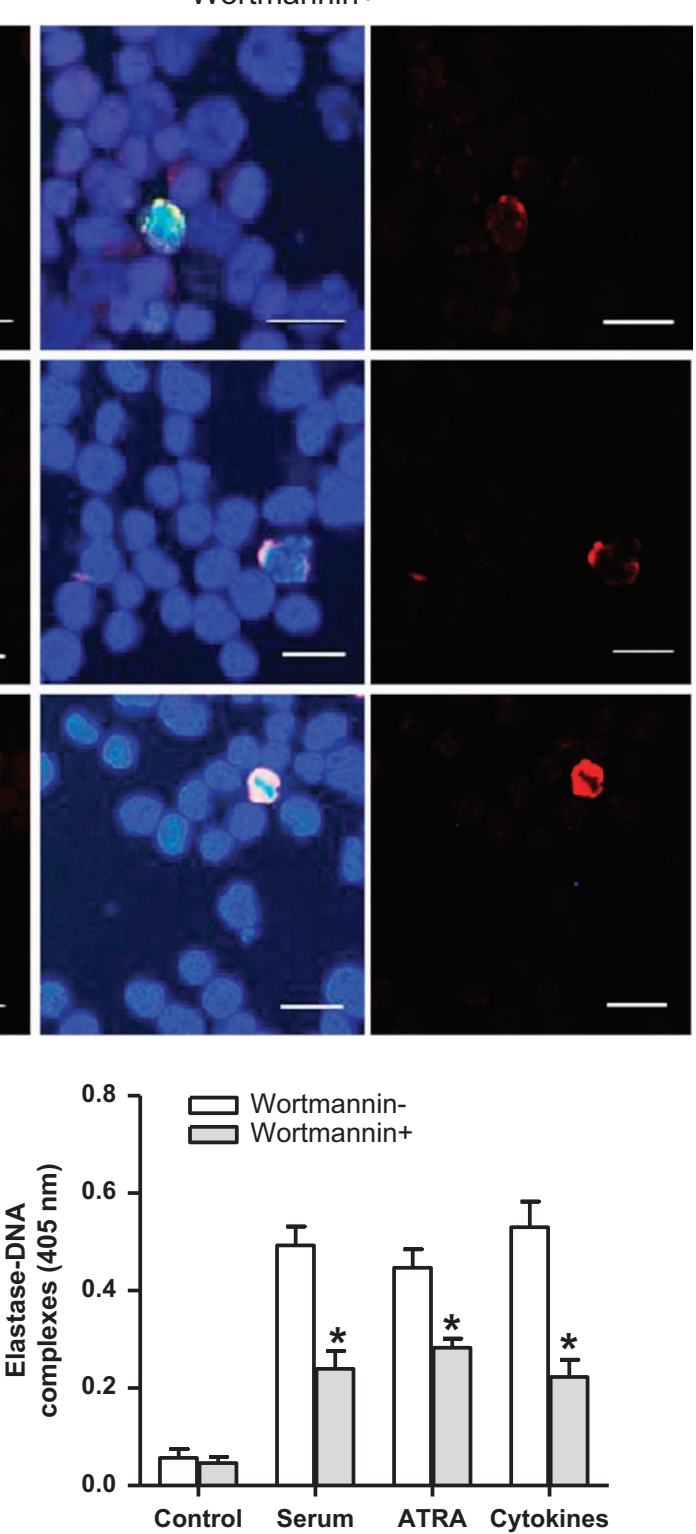

Figure 6 Inhibited autophagy attenuates ETosis. (a) NB4 cells were treated with APL serum for $3 \mathrm{~h}$ in the presence of various autophagy inhibitors, and the percentage of ET-releasing cells and the concentration of elastase-DNA complexes were measured $(n=5)$. All values are means \pm S.D. ${ }^{*} P<0.05$ versus control. (b) NB4 cells were treated with APL serum ( $3 \mathrm{~h})$, ATRA ( 3 days) and TNF- $\alpha$ and IL- $6(1 \mathrm{~h})$ with or without pretreatment with wortmannin ( $1 \mathrm{mg} / \mathrm{ml})$. Immunofluorescence images showed inhibition of autophagy by wortmannin attenuated the aggregation of LC3 (red) and resulted in impairment of ET formation (DAPI/Histone/LC3 merged). (c) Quantification of the percentage of ET-releasing cells and the concentration of elastase-DNA complexes in different treatments $(n=5)$. All values are means \pm S.D. ${ }^{*} P<0.05$ versus wortmannin $(-)$. Bars represent $15 \mu \mathrm{m}$ (b) 
a

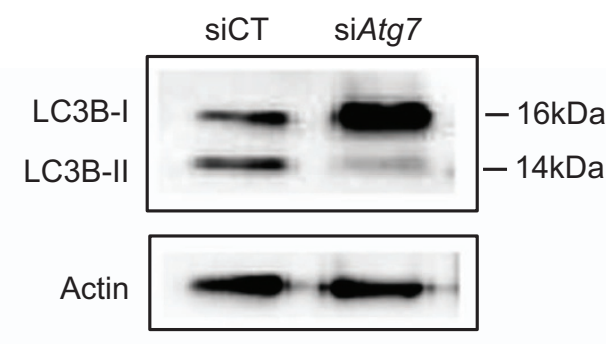

c

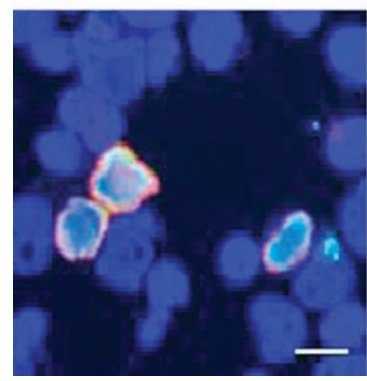

$\mathrm{siCT}$

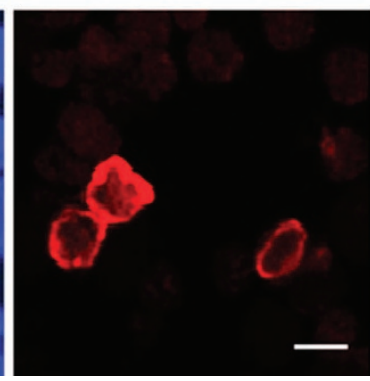

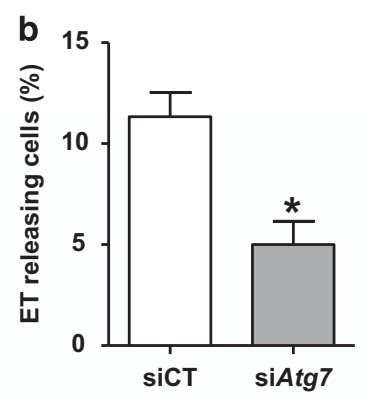
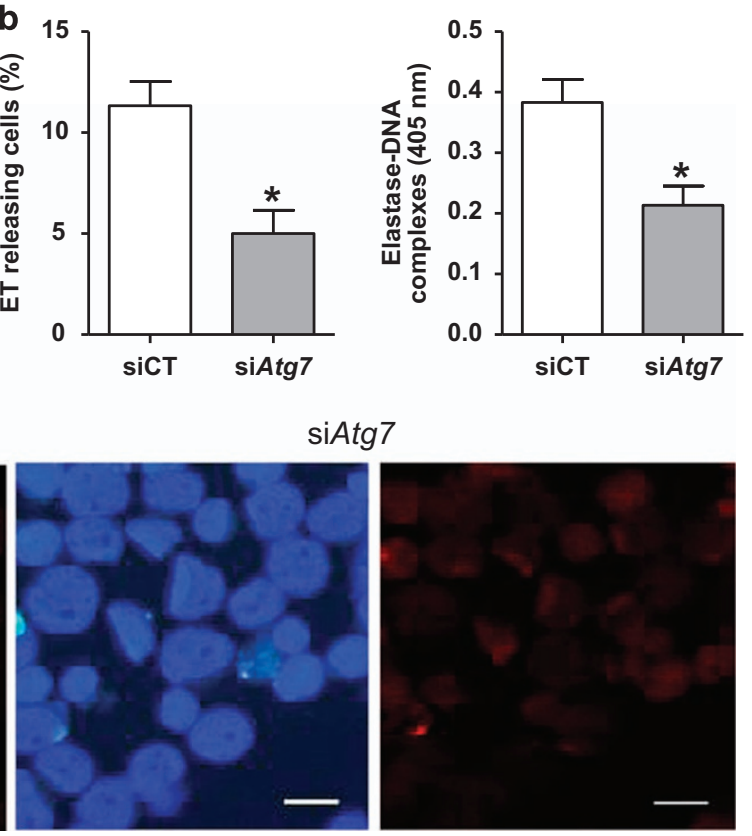

Figure 7 Inhibition of autophagy by knocking down Atg7 decreased ET release. NB4 cells were transiently transfected with Atg7 siRNA (siAtg7) at a concentration of $100 \mathrm{nM}$ and scrambled siRNA (scr) was used as a negative control (siCT). Seventy-two hours after transfection, cells were treated with APL serum for $3 \mathrm{~h}$. (a) The levels of LC3B-I and LC3B-II were detected by western blotting. (b) Quantification of the percentage of ET-releasing cells and the concentration of elastase-DNA complexes $(n=5)$. All values are means \pm S.D. ${ }^{*} P<0.05$ versus control. (c) Immunofluorescence images showed inhibition of autophagy by knocking down Atg7 reduced the aggregation of LC3 (red) and ET formation (DAPI/Histone/LC3 merged). Bars represent $15 \mu \mathrm{m}$

Reagents. RPMI 1640 medium and fetal bovine serum (FBS) were obtained from Gibco (Grand Island, NY, USA). Ficoll-Hypaque, poly-D-lysine, bovine serum albumin (BSA), DAPI, DNR, ATRA, TNF- $\alpha$, IL-6, wortmannin, 3-MA and bafilomycin were from Sigma-Aldrich (St. Louis, MO, USA). PI was from Shanghai Dobio Co., Ltd (Shanghai, China).

FITC-lactadherin was obtained from Haematologic Technologies Inc. (Burlington, VT, USA). Rabbit anti-histone 3-Alexa Fluor 488 mAb (ab154206), rabbit antineutrophil elastase (NE) mAb (ab131260) and rabbit anti-caspase-3 (ab32042), rabbit anti-LC3B (ab48394), rabbit anti-Atg7 (ab52472) were from Abcam (Cambridge, MA, USA). Rabbit anti-LC3 $\alpha / \beta$ polyclonal Ab (sc-292354) was obtained from Santa Cruz Biotechanology Inc. (Santa Cruz, CA, USA). Goat anti-rabbit Cy3 antibody (Invitrogen, Carlsbad, CA, USA) was utilized as a secondary antibody.

Cell and cell culture. Freshly isolated APL blasts were obtained from bone marrow specimens by centrifugation through Ficoll-Hypaque and were used for experiments immediately. In some cases, these cells $\left(5 \times 10^{5} / \mathrm{ml}\right)$ were propagated in complete RPMl 1640 medium supplemented with 20\% FBS, $2 \mathrm{mM}$ L-glutamine and $1 \%$ penicillin-streptomycin solution at $37{ }^{\circ} \mathrm{C}$ in a $5 \% \mathrm{CO}_{2}$ humidified atmosphere. Human APL NB4 cells were maintained under the same conditions except that $10 \%$ FBS was used. In some cases, NB4 cells were treated with $1 \mu \mathrm{M}$ ATRA for differentiation. Polymorphonuclear leukocytes were obtained from peripheral venous blood of healthy subjects using density gradient separation and resuspended in RPMI medium for immediate experiments.

Stimulation and inhibition of NB4 cells. Peripheral venous blood was collected and serum was immediately isolated by centrifugation at $4{ }^{\circ} \mathrm{C}$ at $1400 \times \mathrm{g}$ for $15 \mathrm{~min} .{ }^{50}$ Serum was stored at $-80^{\circ} \mathrm{C}$ till used. NB4/APL cells or neutrophils were incubated with sera at a final concentration of $20 \%$ at $37^{\circ} \mathrm{C}^{50,51}$ In some cases, NB4 cells were stimulated with TNF- $\alpha(100 \mathrm{ng} / \mathrm{ml})$ and IL-6 $(100 \mathrm{ng} / \mathrm{ml})$ for $1 \mathrm{~h}^{54}$ For inhibition assays, the autophagy inhibitor wortmannin (1 mg/ml), 3-MA $(1 \mathrm{mg} / \mathrm{ml})$ or bafilomycin $(1 \mathrm{mg} / \mathrm{ml})$ was incubated with NB4 cells $30 \mathrm{~min}$ before stimulation.

Confocal microscopy. To characterize cell death, the smear of APL or NB4 cells $\left(5 \times 10^{5}\right)$ were incubated with DAPI $(100 \mathrm{ng} / \mathrm{mll})^{20,51}$ or the indicated concentration of PI and FITC-labeled lactadherin. ${ }^{53}$ Cells were washed to remove unbound proteins and analyzed immediately on a Zeiss LSM 510 Meta confocal microscope (Carl Zeiss Jena GmbH, Jena, Germany). The samples were excited with $488 \mathrm{~nm}$ emission line of a krypton-argon laser, and narrow bandpass filters were utilized to restrict emission wavelength overlap. ETosis was distinguished by cells whose nuclei stained with PI became rounded and nuclear contents diffused throughout the cell or by cells stained DAPI with budding and extruding DNA. Apoptosis was defined as the presence of membrane blebbing and nuclei fragmentation. Cells were counted from six random fields in triplicate wells for each condition and expressed as the percentage of total number of cells in the field. ${ }^{20}$

Induction of cell apoptosis and necrosis. APL or NB4 cells were incubated with $1 \mu \mathrm{M}$ DNR for up to $24 \mathrm{~h}$ to induce apoptosis. ${ }^{29}$ Necrosis was elicited in APL cells with four cycles of freezing (liquid nitrogen) and thawing $\left(37^{\circ} \mathrm{C}\right)$, leading to complete fragmentation of the cells. ${ }^{30}$

Transmission electron microscopy. For TEM experiments, cells were collected and double fixed in $2.5 \%$ glutaraldehyde and $1 \% \mathrm{OsO}_{4}$. After dehydration and embedding, ultrathin sections were prepared with a Reichert-Jung Ultracut Ultramicrotome (Leica, Vienna, Austria). Images were observed under a H7650 transmission electron microscope (Hitachi Ltd, Tokyo, Japan).

Immunofluorescence assays. APL or NB4 cells were seeded on glass coverslips with poly-lysine in a 24-well culture plate, treated with stimuli or left unstimulated. Cells were fixed with 4\% PFA, blocked ( $2 \%$ BSA) and incubated with primary anti-histone coupled with Alexa Fluor 488 (1:100); anti-LC3 $\alpha / \beta$ (1:50), anticaspase-3 (1:50) and anti-NE (1:100) were detected with secondary antibodies coupled to Cy3 (1:50). For DNA detection, DAPI (100 ng/ml) was used. Specimens were mounted and analyzed on a fluorescence microscope (Leica, DM400B, Wetzlar, Germany). For quantification, ETs were counted from six different fields in triplicate wells for each condition and expressed as the percentage of ET-forming cells per total number of cells in the field. ${ }^{20}$

Western blotting. Whole-cell lysates were resolved on a denaturing $10 \%$ SDS-PAGE gel and subsequently transferred to polyvinylidene fluoride membranes 
Table 1 APL patients' characteristics

\begin{tabular}{|c|c|c|c|c|c|c|}
\hline No & Sex/age & Diagnosis & $\begin{array}{l}\text { Blasts } \\
\text { (BM\%) }\end{array}$ & $\begin{array}{l}\text { WBC } \\
\left(\times 10^{9} / I\right)\end{array}$ & $\begin{array}{c}\text { Plts } \\
\left(\times 10^{9} / I\right)\end{array}$ & $\begin{array}{l}\mathrm{Hb} \\
(\mathrm{g} / \mathrm{l})\end{array}$ \\
\hline 1 & $F / 48$ & M3/bcr1 & 78 & 17.9 & 26 & 57 \\
\hline 2 & $\mathrm{~F} / 34$ & M3/bcr1 & 61 & 29.3 & 27.4 & 89 \\
\hline 3 & $\mathrm{M} / 37$ & M3/bcr3 & 96 & 1.54 & 11.3 & 64.5 \\
\hline 4 & M/66 & M3/bcr1 & 75 & 2.59 & 5.39 & 44 \\
\hline 5 & $F / 29$ & M3/bcr1 & 94 & 19.6 & 31 & 19 \\
\hline 6 & $\mathrm{~F} / 64$ & M3/bcr1 & 72 & 2.9 & 86 & 102 \\
\hline 7 & $\mathrm{~F} / 24$ & M3/bcr2 & 88 & 32.1 & 19.8 & 65 \\
\hline 8 & $\mathrm{M} / 51$ & M3/bcr1 & 98 & 4.5 & 53 & 60 \\
\hline 9 & M/62 & M3/bcr1 & 57 & 5.6 & 62 & 100 \\
\hline 10 & $\mathrm{~F} / 75$ & M3/bcr2 & 96 & 2.2 & 170 & 79 \\
\hline 11 & $\mathrm{M} / 26$ & M3/bcr1 & 69 & 0.8 & 10.8 & 103 \\
\hline 12 & $F / 25$ & M3/bcr1 & 84 & 12.6 & 148 & 89 \\
\hline 13 & $\mathrm{M} / 45$ & M3/bcr3 & 90 & 0.4 & 27 & 75.2 \\
\hline 14 & $\mathrm{M} / 76$ & M3/bcr2 & 85 & 1.7 & 15 & 76 \\
\hline 15 & $M / 18$ & M3/bcr1 & 73 & 145.2 & 79 & 87 \\
\hline 16 & $M / 33$ & M3/bcr1 & 81 & 0.9 & 10 & 92 \\
\hline $\begin{array}{l}\text { Ref. } \\
\text { range }\end{array}$ & & & $0-0.4$ & $4-10$ & $100-300$ & $110-170$ \\
\hline
\end{tabular}

The main clinical and laboratory features of 16 newly diagnosed APL patients at the moment of bone marrow (BM) aspiration were reported. Blasts, promyelocytes+blasts; WBC, white blood cell; Plts, platelets; Hb, hemoglobin; bcr, breakpoint cluster region (bcr1 = intron 6 , bcr2= exon 6 , bcr3 =intron 3 ).

via semidry transfer. After blocking the membrane at room temperature with $5 \%$ skim milk for $3 \mathrm{~h}$, the membrane was incubated overnight at $4{ }^{\circ} \mathrm{C}$ with anti-caspase$3(1: 500)$ or anti-LC3II (1:1000) antibodies. After incubation with peroxidaseconjugated secondary antibodies at a dilution of 1:2000 for $1 \mathrm{~h}$ and washed three times with PBS, the signals were visualized using enhanced chemiluminescence. ${ }^{26}$

Determination DNA-elastase and cytokine levels in plasma. Plasma from healthy subjects and APL patients were prepared as previously described. ${ }^{54}$ Briefly, blood was collected and plasma was isolated by centrifuging blood for $5 \mathrm{~min}$ at $2300 \times \mathrm{g}$. Plasma supernatant was carefully removed and centrifuged again for $5 \mathrm{~min}$ at $2300 \times \mathrm{g}$ to remove any remaining blood cells. Plasma was stored at $-80^{\circ} \mathrm{C}$ until analysis. Elastase-DNA complexes were detected using a capture ELISA. ${ }^{31,32}$ Briefly, diluted plasma were added to highbinding 96-well ELISA microplates (Greiner Bio-One, Frickenhausen, Germany) pretreated with capture anti-NE (1:2000; Calbiochem, Darmstadt, Germany, rabbit) antibody and blocked with $1 \% \mathrm{BSA} / 0.1 \%$ human serum albumin/PBS for $1-2 \mathrm{~h}$. After overnight incubation and three washes with Tween20 in PBS, secondary peroxidase-labeled of anti-DNA monoclonal antibody (Roche, Indianapolis, IN, USA; Cat. No:11774425001) was added for 30-60 min at RT according to the manufacturer's instructions. The samples were washed three times with PBS per well and the peroxidase substrate (ABTS) of the kit (Roche; Cat. No:11774425001) was added. The absorbance at $405 \mathrm{~nm}$ wavelength was measured using the Tecan microplate reader (Tecan Infinite M200) after 40 min incubation at $37^{\circ} \mathrm{C}$ in the dark. TNF- $\alpha$ and IL- 6 in plasma or culture supernanants were measured with a Human TNF- $\alpha$ ELISA kit and Human IL-6 ELISA kit (Roche) according to the manufacturer's instructions. ${ }^{52}$

siRNA transfection. NB4 cells were transiently transfected with Atg7 siRNA (no. 6604; Cell Signaling Technology, Danvers, MA, USA) at a concentration of $100 \mathrm{nM}$ using Lipofectamine RNAiMAX Transfection Reagent (Life Technology, Grand Island, NY, USA), according to the manufacturer's instruction (RNAiMAX Reverse Transfections Lipofectamine). The cells were also treated with a scrambled siRNA (no. 6568; Cell Signaling Technology) as a negative control. Seventy-two hours after transfection, cells were treated with the APL serum for $3 \mathrm{~h}$. The silencing efficiency of Atg7 was determined by western blot of LC3 expression. ${ }^{35}$

Quantitative real-time PCR. The mRNA levels of Atg7 was measured as previously described. ${ }^{55}$ Briefly, total RNA was extracted using Trizol Reagent (Invitrogen) and reverse transcribed into cDNA using first strand cDNA synthesis kit (Roche Diagnostics) as per the manufacturer's instructions. Real-time PCR was performed in an ABI PRISM 5700 Sequence Detector System (Applied Biosystems) using the SYBR Green detection protocol as outlined by the manufacturer. A genespecific primer for Atg7 was designed using the Primer Express software (Applied Biosystems). Quantitative normalization of the CDNA in each sample was performed using the GAPDH gene as an internal control. Real-time PCR assays were performed in duplicate for each sample, and the mean value was used for the calculation of mRNA expression levels.

Statistical analysis. Numerical variables were tested for normal distribution with the Kolmogorov-Smirnov test. Data are expressed as mean \pm S.D. for at least three replicates, and statistical analysis was made by $t$-test or ANOVA as appropriate.

\section{Conflict of Interest \\ The authors declare no conflict of interest.}

Acknowledgements. We thank Yanming Xue for the sample collection, and Shouchen Zhang, Yueming Chi, Lei Gao, Jiangtian Tian, Ji Li and Hulun Li for excellent technical assistance. We thank James O'Kelly (Los Angeles, CA, USA) for providing NB4 cells. This work was supported by grants from the National Science Foundation of China $(81270588,81470301)$ and Graduate Innovation Fund of Harbin Medical University (YJSCX2014-02HYD).

\section{Author contributions}

RM designed the research, performed experiments, analyzed results, made the figures and wrote the paper; JS obtained funding, designed the study, performed some experiments, analyzed results, made the figures and revised the manuscript; JZ provided partial funding support; ZY, TL, MC, XW, RD, SF, YB and JK performed some experiments; BY, SY, JW and VN analyzed data and revised the manuscript; YS, YZ and LZ made the figures and analyzed data.

1. Goddard $A D$, Borrow J, Freemont $P$, Solomon $E$. Characterization of a zinc finger gene disrupted by the $t(15 ; 17)$ in acute promyelocytic leukemia. Science 1991; 254: 1371-1374.

2. Warrell RP Jr, de The H, Wang ZY, Degos L. Acute promyelocytic leukemia. N Engl J Med 1993; 329: 177-189.

3. Degos L, Dombret H, Chomienne C, Daniel MT, Micléa JM, Chastang C et al. ATRA as a differentiation agent in the treatment of acute promyelocytic leukemia. Blood 1995; 85: 2643-2653.

4. Lengfelder E, Hofmann W, Nowak D. Impact of arsenic trioxide in the treatment of acute promyelocytic leukemia. Leukemia 2012; 26: 433-442.

5. Zhu HH, Qin YZ, Huang XJ. Resistance to arsenic therapy in acute promyelocytic leukemia. N Engl J Med 2014; 370: 1864-1866.

6. Lehmann-Che J, Bally $\mathrm{C}$, de Thé $\mathrm{H}$. Resistance to therapy in acute promyelocytic leukemia N Engl J Med 2014; 371: 1170-1172.

7. Daver N, Cortes J, Ravandi F, Patel KP, Burger JA, Konopleva M et al. Secondary mutations as mediators of resistance to targeted therapy in leukemia. Blood 2015; 125: 3236-3245.

8. Brinkmann V, Reichard U, Goosmann C, Fauler B, Uhlemann Y, Weiss DS et al. Neutrophil extracellular traps kill bacteria. Science 2004; 303: 1532-1535.

9. Fuchs TA, Abed U, Goosmann C, Hurwitz R, Schulze I, Wahn V et al. Novel cell death program leads to neutrophil extracellular traps. J Cell Biol 2007; 176: 231-241.

10. Aleyd E, van Hout MW, Ganzevles SH, Hoeben KA, Everts V, Bakema JE et al. IgA enhances NETosis and release of neutrophil extracellular traps extracellular traps by polymorphonuclear cells via Fca receptor I. J Immunol 2014; 192: 2374-2383.

11. Barquero-Calvo E, Mora-Cartín R, Arce-Gorvel V, de Diego JL, Chacón-Díaz C, ChavesOlarte $\mathrm{E}$ et al. Brucella abortus induces the premature death of human neutrophils through the action of its lipopolysaccharide. PLOS Pathog 2015; 11: e1004853.

12. Yost CC, Cody MJ, Harris ES, Thornton NL, McInturff AM, Martinez ML et al. Impaired neutrophil extracellular trap (NET) formation: a novel innate immune deficiency of human neonates. Blood 2009; 113: 6419-6427.

13. Schauer C, Janko C, Munoz LE, Zhao Y, Kienhöfer D, Frey B et al. Aggregated neutrophil extracellular traps limit inflammation by degrading cytokines and chemokines. Nat Med 2014; 20: 511-517.

14. Martinod K, Wagner DD. Thrombosis: tangled up in NETs. Blood 2014; 123: 2768-2776.

15. Inoue $Y$, Yu YM, Kurihara T, Vasilyev A, Ibrahim A, Oklu R et al. Kidney and liver injuries after major burns in rats are prevented by Resolvin D2. Crit Care Med 2016; 44: e241-e252.

16. Simon D, Radonjic-Hösli S, Straumann A, Yousefi S, Simon HU. Active eosinophilic esophagitis is characterized by epithelial barrier defects and eosinophil extracellular trap formation. Allergy 2015; 70: 443-452. 
17. von Köckritz-Blickwede M, Goldmann O, Thulin P, Heinemann K, Norrby-Teglund A, Rohde $\mathrm{M}$ et al. Phagocytosis-independent antimicrobial activity of mast cells by means of extracellular trap formation. Blood 2008; 111: 3070-3080.

18. Webster SJ, Daigneault M, Bewley MA, Preston JA, Marriott HM, Walmsley SR et al. Distinct cell death programs in monocytes regulate innate responses following challenge with common causes of invasive bacterial disease. J Immunol 2010; 185: 2968-2979.

19. Simon D, Simon HU, Yousefi S. Extracellular DNA traps in allergic, infectious, and autoimmune diseases. Allergy 2013; 68: 409-416.

20. Demers M, Krause DS, Schatzberg D, Martinod K, Voorhees JR, Fuchs TA et al. Cancers predispose neutrophils to release extracellular DNA traps that contribute to cancerassociated thrombosis. Proc Natl Acad Sci USA 2012; 109: 13076-13081.

21. McInturff AM, Cody MJ, Elliott EA, Glenn JW, Rowley JW, Rondina MT et al. Mammalian target of rapamycin regulates neutrophil extracellular trap formation via induction of hypoxiainducible factor 1 alpha. Blood 2012; 120: 3118-3125.

22. Wang Y, Li M, Stadler S, Correll S, Li P, Wang D et al. Histone hypercitrullination mediates chromatin decondensation and neutrophil extracellular trap formation. J Cell Biol 2009; 184 205-213.

23. Kawakami T, He J, Morita H, Yokoyama K, Kaji H, Tanaka C et al. Rab27 is essential for the formation of neutrophil extracellular traps (NETs) in neutrophil-like differentiated HL60 cells. PLoS One 2014; 9: e84704.

24. Nakayama T, Saitoh H. Tunicamycin-induced neutrophil extracellular trap (NET)-like structures in cultured human myeloid cell lines. Cell Biol Int 2015; 39: 355-359.

25. Nakayama T, Saitoh N, Morotomi-Yano K, Yano KI, Nakao M, Saitoh H. Nuclear extrusion precedes discharge of genomic DNA fibers during tunicamycin-induced neutrophil extracellular trap-osis (NETosis)-like cell death in cultured human leukemia cells. Cell Biol Int 2016; 40: 597-602.

26. Wang Z, Cao L, Kang R, Yang M, Liu L, Zhao $Y$ et al. Autophagy regulates myeloid cell differentiation by $\mathrm{p} 62 / \mathrm{SQSTM} 1-$ mediated degradation of PML-RAR $\alpha$ oncoprotein. Autophagy 2011; 7: 401-411.

27. Huang Y, Hou JK, Chen TT, Zhao XY, Yan ZW, Zhang J et al. PML-RAR $\alpha$ enhances constitutive autophagic activity through inhibiting the Akt/mTOR pathway. Autophagy 2011; 7: $1132-1144$

28. Gañán-Gómez I, Estañ-Omaña MC, Sancho P, Aller P, Boyano-Adánez MC. Mechanisms of resistance to apoptosis in the human acute promyelocytic leukemia cell line NB4. Ann Hemotol 2015; 94: 379-392.

29. Zhou J, Shi J, Hou J, Cao F, Zhang Y, Rasmussen JT et al. Phosphatidylserine exposure and procoagulant activity in acute promyelocytic leukemia. J Thromb Haemost 2010; 8: 773-782.

30. Sangaletti S, Tripodo C, Chiodoni C, Guarnotta C, Cappetti B, Casalini P et al. Neutrophi extracellular traps mediate transfer of cytoplasmic neutrophil antigens to myeloid dendritic cells toward ANCA induction and associated autoimmunity. Blood 2012; 120 : 3007-3018.

31. Kessenbrock K, Krumbholz M, Schönermarck U, Back W, Gross WL, Werb Z et al. Netting neutrophils in autoimmune small-vessel vasculitis. Nat Med 2009; 15: 623-625.

32. Yoo DG, Floyd M, Winn M, Moskowitz SM, Rada B. NET formation induced by Pseudomonas aeruginosa cystic fibrosis isolates measured as release of myeloperoxidase-DNA and neutrophil elastase-DNA complexes. Immunol Lett 2014; 160: 186-194.

33. Hui H, Yang H, Dai Q, Wang Q, Yao J, Zhao K et al. Oroxylin A inhibits ATRA-induced IL-6 expression involved in retinoic acid syndrome by down-regulating CHOP. Gene 2014; 551 230-235.

34. Remijsen Q, Vanden Berghe T, Wirawan E, Asselbergh B, Parthoens E, De Rycke R et al. Neutrophil extracellular trap cell death requires both autophagy and superoxide generation. Cell Res 2011; 21: 290-304.

35. Chen S, Dobrovolsky VN, Liu F, Wu Y, Zhang Z, Mei N et al. The role of autophagy in usnic acid-induced toxicity in hepatic cells. Toxicol Sci 2014; 142: 33-44.

36. Gould TJ, Vu T, Swystun LL, Dwivedi DJ, Mai SH, Ji Weitz et al. Neutrophil extracellular traps promote thrombin generation through platelet-dependent and platelet-independen mechanisms. Arterioscler Thromb Vsac Biol 2014; 34: 1977-1984.

37. Fuchs TA, Kremer Hovinga JA, Schatzberg D, Wagner DD, Lämmle B. Circulating DNA and myeloperoxidase indicate disease activity in patients with thrombotic microangiopathies. Blood 2012; 120: 1157-1164.

38. Stakos DA, Kambas K, Konstantinidis T, Mitroulis I, Apostolidou E, Arelaki S et al. Expression of functional tissue factor by neutrophil extracellular traps in culprit artery of acute myocardial infarction. Eur Heart J 2015; 36: 1405-1414.
39. Jiménez-Alcázar M, Napirei M, Panda R, Köhler EC, Kremer Hovinga JA, Mannherz HG et al. Impaired DNase-1-mediated degradation of neutrophil extracellular traps is associated with acute thrombotic microangiopathies. J Thromb Haemost 2015; 13: 732-742.

40. Savchenko AS, Martinod K, Seidman MA, Wong SL, Borissoff Jl, Piazza G et al. Neutrophil extracellular traps form predominantly during the organizing stage of human venous thromboembolism development. J Thromb Haemost 2014; 12: 860-870.

41. Demers Melanie, Wagner DD. NETosis: a new factor in tumor progression and cancerassociated thrombosis. Semin Thromb Hemost 2014; 40: 277-283.

42. Allam R, Kumar SV, Darisipudi MN, Anders HJ. Extracellular histones in tissue injury and inflammation. J Mol Med 2014; 92: 465-472.

43. Hashiba M, Huq A, Tomino A, Hirakawa A, Hattori T, Miyabe H et al. Neutrophil extracellular traps in patients with sepsis. J Surg Res 2015; 194: 248-254.

44. Orfali N, O'Donovan TR, Nyhan MJ, Britschgi A, Tschan MP, Cahill MR et al. Induction of autophagy is a key component of all-trans-retinoic acid induced differentiation in leukemia cells and a potential target for pharmacological modulation. Exp Hematol 2015; 43: 781-793.

45. Levine B, Kroemer G. Autophagy in the pathogenesis of disease. Cell 2008; 132: 27-42.

46. Kroemer G, Galluzzi L, Vandenabeele P, Abrams J, Alnemri ES, Baehrecke EH et al. Classification of cell death: recommendations of the Nomenclature Committee on Cell Death. Cell Death Differ 2009; 16: 3-11.

47. Mijaljica D, Devenish RJ. Nucleophagy at a glance. J Cell Sci 2013; 126: 4325-4330.

48. Torgersen ML, Simonsen A. Friend or foe in the treatment of fusion protein-associated leukemias? Autophagy 2013; 9: 2175-2177.

49. Brigger D, Schläfli AM, Garattini E, Tschan MP. Activation of RAR $\alpha$ induces autophagy in SKBR3 breast cancer cells and depletion of key autophagy genes enhances ATRA toxicity. Cell Death Dis 2015; 6: e1861.

50. Kambas K, Chrysanthopoulou A, Vassilopoulos D, Apostolidou E, Skendros P, Girod A et al. Tissue factor expression in neutrophil extracellular traps and neutrophil derived microparticles in antineutrophil cytoplasmic antibody associated vasculitis may promote thromboinflammation and the thrombophilic state associated with the disease. Ann Rheum Dis 2014; 73: 1854-1863.

51. Chen G, Zhang DC, Fuchs TA, Wagner DD, Frenette PS. Heme-induced neutrophil extracellular traps contribute to the pathogenesis of sickle cell disease. Blood 2014; 123: 3818-3827.

52. De Meyer SF, Suidan GL, Fuchs TA, Monestier M, Wagner DD. Extracellular chromatin is an important mediator of ischemic stroke in mice. Arterioscler Thromb Vasc Biol 2012; 32: 1884-1891.

53. Shi J, Shi Y, Waehrens LN, Rasmussen JT, Heegaard CW, Gilbert GE. Lactadherin detects early phosphatidylserine exposure on immortalized leukemia cells undergoing programmed cell death. Cytometry A 2006; 69: 1193-1201.

54. Khandpur R, Carmona-Rivera C, Vivekanandan-Giri A, Gizinski A, Yalavarthi S, Knight JS et al. NETs are a source of citrullinated autoantigens and stimulate inflammatory responses in rheumatoid arthritis. Sci Transl Med 2013; 5: 178ra40.

55. Jacquel $A$, Herrant $M$, Defamie V, Belhacene $N$, Colosetti $P$, Marchetti $S$ et al. A survey of the signaling pathways involved in megakaryocytic differentiation of the human K562 leukemia cell line by molecular and c-DNA array analysis. Oncogene 2006; 25 : 781-794.

Cell Death and Disease is an open-access journal published by Nature Publishing Group. This work is licensed under a Creative Commons Attribution 4.0 International License. The images or other third party material in this article are included in the article's Creative Commons license, unless indicated otherwise in the credit line; if the material is not included under the Creative Commons license, users will need to obtain permission from the license holder to reproduce the material. To view a copy of this license, visit http://creativecommons.org/licenses/by/4.0/

(C) The Author(s) 2016 